Research Article

\title{
Micropore Structure and Fractal Characteristics of Low-Permeability Coal Seams
}

\author{
Guang-zhe Deng $\mathbb{D}^{1,2}$ and Rui Zheng $\mathbb{D}^{1,2}$ \\ ${ }^{1}$ College of Energy Science and Engineering, Xi'an University of Science and Technology, Xi'an 710054, China \\ ${ }^{2}$ Key Laboratory of Western Mine Exploitation and Hazard Prevention, Ministry of Education, Xi'an 710054, China \\ Correspondence should be addressed to Rui Zheng; zhengruiyz@163.com
}

Received 17 May 2018; Revised 2 September 2018; Accepted 10 September 2018; Published 16 October 2018

Academic Editor: Guoqiang Xie

Copyright (C) 2018 Guang-zhe Deng and Rui Zheng. This is an open access article distributed under the Creative Commons Attribution License, which permits unrestricted use, distribution, and reproduction in any medium, provided the original work is properly cited.

\begin{abstract}
With the raw coal from a typical low-permeability coal seam in the coalfield of South Junger Basin in Xinjiang as the research object, this paper examined six kinds of coal samples with different permeabilities using a scanning electron microscope and a low-temperature nitrogen adsorption test that employed a JSM-6460LV high-resolution scanning electron microscope and an ASAP2020 automatic specific surface area micropore analyzer to measure all characteristic micropore structural parameters. According to fractal geometry theory, four fractal dimension calculation models of coal and rock were established, after which the pore structure characteristic parameters were used to calculate the fractal dimensions of the different coal seams. The results show that (1) the low-permeability coal seam in the coalfield of South Junger Basin in Xinjiang belongs to mesoporous medium, with a certain number of large pores and no micropores. The varying adsorption capacities of the different coal seams were positively correlated with pore volume, surface area, and the mesoporous surface area proportions, from which it was concluded that mesopores were the main contributors to pore adsorption in low-permeability coal seams. (2) The raw coal pore fractal dimension had a negative linear relationship to average pore size, a positive linear relationship with total pore volume, total surface area, and adsorption capacity, and a positive correlation with the mesoporous surface area proportion; that is, the higher the fractal dimension, the larger the pore volume and surface area of the raw coal. (3) The permeability of the low-permeability coal seam had a phase correlation with the micropore development degree; that is, the permeability had a phase negative correlation with the pore distribution fractal dimension, and there was a positive correlation between permeability and porosity. These results are of theoretical significance for the clean exploitation of lowpermeability coal seam resources.
\end{abstract}

\section{Introduction}

Coal is a complex porous medium, with its macroscopic physical properties (porosity, permeability, and adsorbability) and its physical and mechanical properties being closely related to its microscopic pore structure characteristics. It is important to study the pore structure characteristics of the coal seam for understanding and interpreting coal reservoir [1].

Close research attention has been paid to the relationships between micropore structures and the macroscopic physical properties of coal and rock mass. While it is known that the pore structures of coal and rock mass are complex and have obvious heterogeneity, it has been difficult to describe and characterize these pore structures using traditional methods. However, fractal theory has been found to be an effective method for characterizing complex porous media; for example, it can be used for pore structure identification, diffusion coefficient, permeability coefficient measurement, and so on [2-5]. The fractal dimension is a quantitative descriptive parameter for specific fractal characteristics. Therefore, based on fractal theory, the pore structures of sandstone were analyzed, from which a new method for simultaneously measuring porosity and pore surface fractal dimensions was proposed, which allowed for the relationships between the fractal dimensions and 
residual water saturation to be identified [6-8]. A study of four bituminous coals and oxidized bituminous coal samples at $270^{\circ} \mathrm{C}$ was able to determine the fractal dimensions and fractal distribution sensitivities to oxidation treatments [9]. Based on the creep fracture damage model of a jointed rock mass, the results show that the greater the number of rock joints, the larger the fractal dimensions, the more the fracture energy absorbs material [10-13]. Coal pore structure has been analyzed using mercury injection experiments, which allowed for the fractal dimensions of the pore coal body surface to be calculated and the pore structure characteristics to be quantitatively characterized $[14,15]$. The relationships between the adsorption characteristics of coal samples and the fractal dimension of low-temperature pore surfaces have been established using nitrogen adsorption tests [16-21], and using digital core technology, the relationships between the fractal dimension of pore diameter and permeability have been established [22, 23]. Fractal theory has also been employed to determine the relationships between pore fractal dimensions and permeability [24-26], from which it was found that the compressibility, hardness, and porosity of coal bodies were related to the fractal dimensions [27-29]. A study on the influence of confined pressure and pore water pressure on the coal sample structure and percolation characteristics established a quantitative relationship between pore structure fractals and coal sample permeability $[30,31]$. According to the pore structure characteristics of low-permeability coal seams, a 3D pore model for low-permeability coal was constructed, and the influence of porosity on mechanical properties of coal was discussed [32].

Although there has been significant research on the physical properties of coal seams, there has been little research focused on the microscopic pore structures of lowpermeability coal seams and the effect of these on the macroscopic exploitation and utilization of the coal seams. Therefore, to further explore the relationships between the microstructure characteristics and the macroscopic physical properties of low-permeability coal seams, this paper used the low-permeability coal seam in the coalfield of South Junger Basin in Xinjiang to systematically analyze the coal's physical characteristics and pore structure using an MTS-815 servo test system, a scanning electron microscope, and a surface microporous fractal instrument, which allowed for all kinds of fractal models used to study and explain the micropore structure of the coal seam. The fractal characteristics of pore structure in low-permeability coal seams and the relationships between the pore structure and the macroscopic physical parameters are also discussed. These results can greatly assist in the interpretation and prediction of the macroscopic properties in coal seams.

\section{Fractal Description of Coal and Rock Pore Structures}

In fractal geometry, the fractal dimension is the objective tool used to measure the degree of "irregularity" and "complexity" in two fractal sets. The fractal dimension definition has the following relations [33]:

$$
\phi=\left(\frac{\lambda_{\min }}{\lambda_{\max }}\right)^{D_{\mathrm{e}}-D_{\mathrm{f}}},
$$

where $\phi$ is porosity, $D_{e}$ is the Euclidean space dimension, and $D_{f}$ is the fractal dimension. In twodimensional space, $D_{\mathrm{e}}=2,1<D_{\mathrm{f}}<2$. In three dimensions, $D_{\mathrm{e}}=3,2\left\langle D_{\mathrm{f}}\left\langle 3 ; \lambda_{\min } / \lambda_{\max }\right.\right.$ are the minimum and maximum pore diameters.

2.1. Fractal Dimension Pore Distribution Model. To assess the fractal dimension pore distribution, which reflects the inhomogeneity of the pores, the fractal box dimension method has been a widely used fractal measurement method, the rationale for which is as follows.

When the fractal figure covers the fractal curve image with a square lattice of a certain scale, some of the mesh may contain part of the curve, while other parts of the mesh remain empty, with the number of nonempty mesh increasing as the mesh side length gradually reduces. If the side length of a square mesh is $r$, and the number of nonempty mesh is $N(r)$, then the fractal box dimension is [34]

$$
D=-\lim _{r \longrightarrow 0} \frac{\ln N(r)}{\ln r} .
$$

The corresponding $N(r)$ value is calculated for different grid side lengths $r$, the logarithmic coordinate curves of $r$ and $N(\geq r)$ are given, and the relation is obtained through fitting [35]:

$$
\ln (N(\geq r))=c-D \ln (r) .
$$

The slope $k$ of Equation (3) is used to fit the straight line, with the box dimension $D=-k$ and having a value between 1 and 2 . In this paper, $D_{\mathrm{D}}$ is the fractal dimension of pore distribution.

2.2. Fractal Dimension Pore Volume Model. From the fractal definition, the density function of the pore radius distribution in porous media has the following relationships [36]:

$$
f(r)=c r^{-D-1},
$$

where $r$ is the pore radius, $D$ is the pore fractal dimension, and $c$ is a constant.

If the pore gap is a sphere, the cumulative pore volume is the integral of the radius distribution density function to the radius; therefore, the cumulative pore volume $V(\leq r)$ with a pore radius less than $r$ can be obtained as follows:

$$
V(\leq r)=\int_{r_{\min }}^{r} f(r) a r^{3} d r=\frac{a c}{3-D}\left(r^{3-D}-r_{\min }^{3-D}\right) .
$$

The cumulative total pore volume is $V$ :

$$
V=\frac{a c}{3-D}\left(r_{\max }^{3-D}-r_{\min }^{3-D}\right)
$$


Putting Equations (5) and (6) into the following formula, the expression for the cumulative pore volume fraction $N_{\mathrm{V}}$ with a pore radius of no more than $r$ can be obtained:

$$
N_{\mathrm{V}}=\frac{V(\leq r)}{V}=\frac{r^{3-D}-r_{\min }^{3-D}}{r_{\max }^{3-D}-r_{\min }^{3-D}} .
$$

Due to the strong heterogeneity in coal and rock media, the maximum/minimum pore size varies greatly; that is, $r_{\max } \gg r_{\min }$; therefore, Equation (7) can be simplified to

$$
N_{\mathrm{V}}=\left(\frac{r}{r_{\max }}\right)^{3-D} \text {. }
$$

Equation (9) is then obtained from the logarithm of Equation (8):

$$
\ln \left(N_{\mathrm{V}}\right)=(3-D) \ln (r)+C_{1},
$$

where $C_{1}=(D-3) \ln \left(r_{\max }\right)$ is a constant. The fractal dimension of the cumulative pore volume is $D=3-k$, with the value being between 2 and 3 . In this paper, $D_{\mathrm{V}}$ is the fractal dimension of pore volume.

2.3. Fractal Dimension Pore Area Model. If the pore is a sphere, a cumulative pore area $S(\geq r)$ with a pore diameter of not less than $r$ can be obtained:

$$
S(\geq r)=\int_{r}^{r_{\max }} f(r) a r^{2} d r=\frac{a c}{2-D}\left(r_{\max }^{2-D}-r^{2-D}\right) .
$$

The cumulative total pore area is $S$ :

$$
S=\frac{a c}{2-D}\left(r_{\max }^{2-D}-r_{\min }^{2-D}\right)
$$

Putting Equations (10) and (11) into the following formula, the expression for the cumulative pore area fraction $N_{\mathrm{S}}$ with a pore radius of not less than $r$ can be obtained:

$$
N_{\mathrm{S}}=\frac{S(\geq r)}{S}=\frac{r_{\max }^{2-D}-r^{2-D}}{r_{\max }^{2-D}-r_{\min }^{2-D}} .
$$

As $r_{\max } \gg r_{\min }$, Equation (12) can be simplified to

$$
N_{\mathrm{S}}=1-\left(\frac{r}{r_{\max }}\right)^{2-D} \text {. }
$$

Equation (14) is then obtained from the logarithm of Equation (13):

$$
\ln \left(1-N_{\mathrm{S}}\right)=(2-D) \ln (r)+C_{2},
$$

where $C_{2}=(D-2) \ln \left(r_{\max }\right)$ is a constant. The fractal dimension of the cumulative pore area is $D=2-k$, with its value being between 1 and 2 . In this paper, $D_{\mathrm{A}}$ is the fractal dimension of pore area.

2.4. Fractal Dimension Pore Surface Model. Fractal theory states that the surface fractal dimension does not theoretically depend on the size of the pores or the surface; rather, it is an intrinsic characteristic of the surface itself as it is a measure of surface roughness. The FrenkelHalsey-Hill (FHH) model is an important method for obtaining the specific surface fractal dimension of complex fractal porous media [37], the equation for which is [38]

$$
\ln V=-f(D) \ln \left(\ln \frac{P_{0}}{P}\right)+C,
$$

where $V$ represents the adsorption volume at the equilibrium pressure $P, P_{0}$ is the vapor saturation pressure, $C$ is the constant, $P_{0} / P$ is the relative pressure, and $f(D)$ is the fractal dimension $D$ expression.

The fractal dimension $D$ was introduced into the adsorption isotherm equation for microporous solid surfaces [39-41]; $f(D)=3-D$; therefore, the fractal $\mathrm{FHH}$ equation can be written as $[42,43]$

$$
\ln V=(D-3) \ln \left(\ln \frac{P_{0}}{P}\right)+C .
$$

When the low-temperature nitrogen adsorption data, $\ln V$ and $\ln \left(\ln \left(P_{0} / P\right)\right)$, were plotted, the fitting line slope was $k$, and the fractal pore surface dimension was calculated as $D=k+3$, with its value being between 2 and 3 . In this paper, $D_{S}$ is the fractal dimension of pore surface.

\section{Fractal Characteristics of the Outer Pores in Low-Permeability Coal Seams}

3.1. Coal Sampling. In this paper, the typical lowpermeability coal seam coal samples $\mathrm{B} 1+2$ and $\mathrm{B} 3+6$ were taken as the research objects. The coal sample permeability was measured using an MTS-815 servo test system, which showed that the coal test samples belonged to the lowpermeability coal seam, with the permeability coal seam relationships being B-3 $<$ B- $4<$ B- $1<$ B-5 $<$ B- $2<$ B-6 (Table 1 ).

3.2. Electron Microscope Scanning Experiment. A coal sample is usually broken apart to obtain a natural section, after which the sample is scanned to ensure that the scanned image is closer to the true shape of the pore. The pore and fissure structural characteristics observed from coal sample 16 were found to be accurate and stable [44]. In this paper, the coal sample was first cut into 16 sections using small grinding wheels, after which the coal sample sections were broken to form a natural section. To ensure image clarity so as to be able to count the scanning data, the natural sections needed to be smooth.

A high-resolution scanning electron microscope test system (Figure 1) was used to scan the natural coal sample sections from 6 different coal seams and obtain the SEM images (Figure 2).

The pore structure was analyzed at 1000 times magnification to be able to analyze the low-permeability coal seam surface pore structure characteristics. The B-1 coal samples were found to have mainly intergranular pores, more mineral crystal particles, and developing cracks and microcracks. The B-2 coal sample was denser, with a smaller quantity of intergranular minerals, a large crack cutting surface or even holes, more regular flat cracks, a stacked fracture, and strong toughness. The B-3 coal sample had a large amount of distributed residual tissue 
TABLe 1: Permeability of different coal samples.

\begin{tabular}{lcccc}
\hline Coal sample & Porosity (\%) & Permeability $(\mathrm{md})$ & Appraise & Classify \\
\hline B-1 & 8.2 & 3.75 & & \\
B-2 & 7.7 & 9.77 & Permeability range & Ultralow-permeability reservoir \\
B-3 & 7.0 & 0.29 & & \\
B-4 & 5.0 & 0.43 & Poor permeability & Low-permeability reservoir \\
B-5 & 6.3 & 5.32 & 13.2 & \\
B-6 & 6.8 & &
\end{tabular}

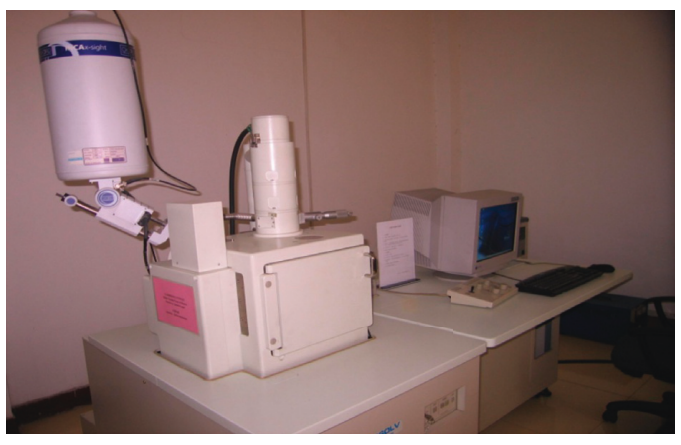

(a)

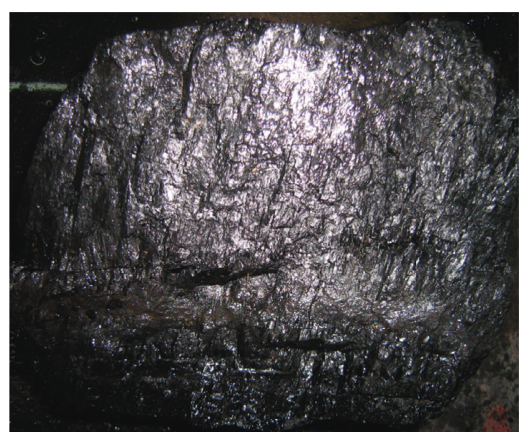

(b)

FIGURE 1: SEM test system and raw coal sample.

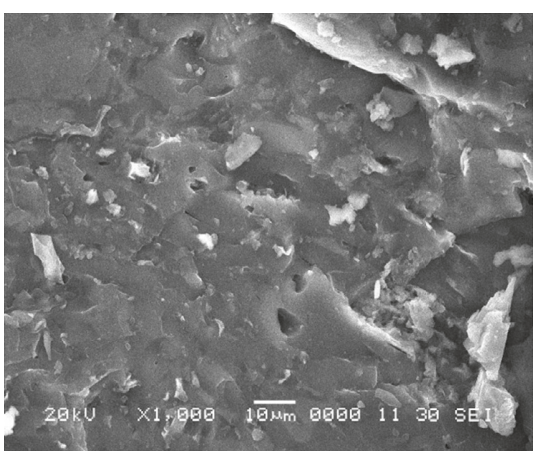

(a)

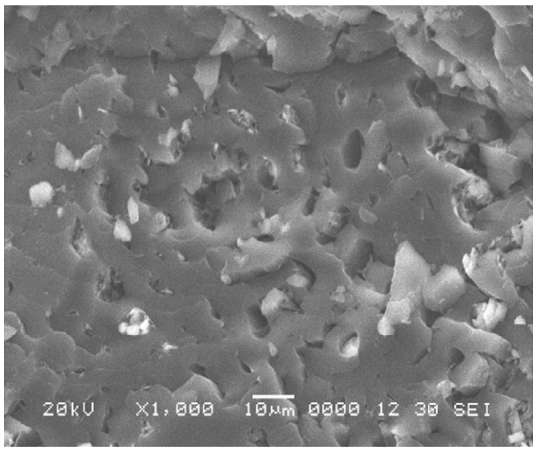

(d)

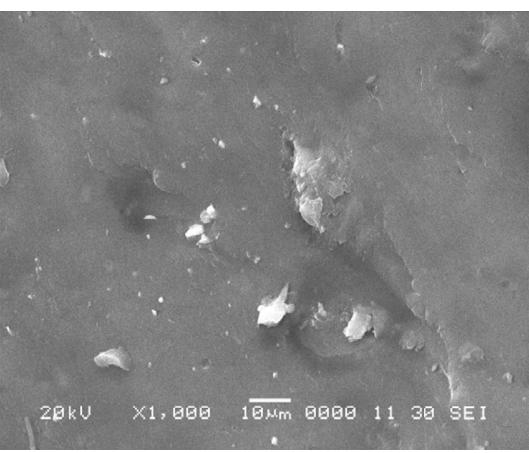

(b)

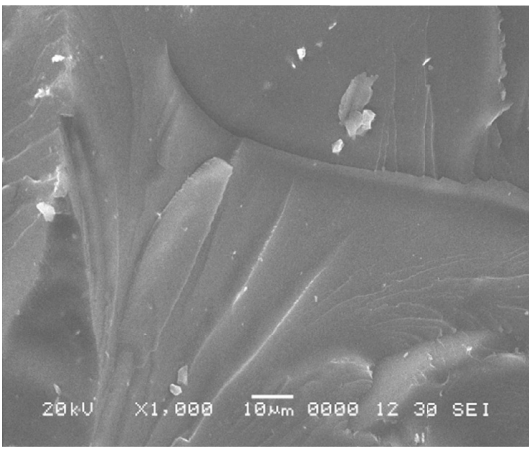

(e)

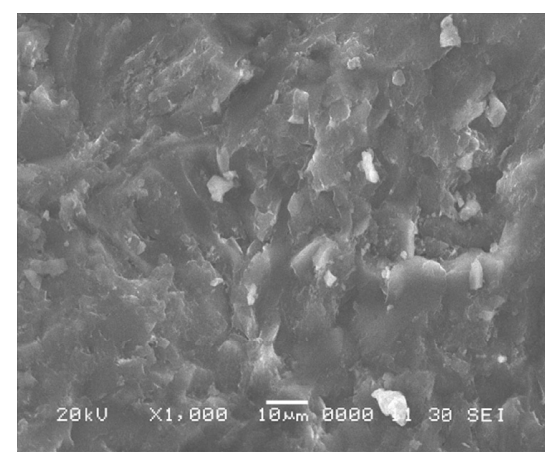

(c)

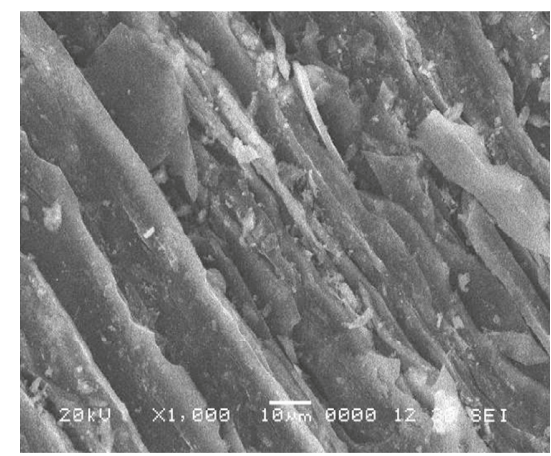

(f)

Figure 2: Raw coal sample SEM images (×1000). (a) B-1 coal sample. (b) B-2 coal sample. (c) B-3 coal sample. (d) B-4 coal. (e) B-5 coal sample. (f) B-6 coal sample.

plant pores; from the precipitation of the granular minerals, it is possible to see the xylem retained by the structural silk body and the phloem cell cavity; therefore, the pore level was stronger and more developed, and there were more micropores. The B-4 coal samples were relatively dense, mainly intergranular pores that had a larger pore size and a different pore shape. There were also a small quantity of intergranular pores that had been caused by 
mineral crystallization, layered cracks, and a small distribution of a number of mineral particles. The B-5 coal sample was compact, with minerals in the intergranular inclusions, a large crack cutting surface, more regular cracks, laminated fractures, and a stronger toughness and stronger crack than the B-2 coal sample. The B-6 coal sample and the B-3 coal sample were similar, as they both had a large distribution of plant residual tissue pores, a precipitation of granular minerals, a structural silk body with retained xylem, and various cellular lumen tissue phloem. Larger more-developed micropores could also be seen at certain magnification rates.

\subsection{Fractal Dimension Calculation and Analysis. Using} an Ostu threshold binarization processing method and MATLAB programming, the SEM images for each coal sample at different magnification rates were processed, and the corresponding binary images were obtained (Figure 3), in which the black area are the macropores and the white area is the coal skeleton (including the filling mineral composition).

The fractal dimension of pore distribution for the binary sample images was calculated using the "box-counting" algorithm in Fractal Fox 2.0 software, from which it was found that the fractal dimension of pore distribution was between 1 and 2 . The software calculation interface and results are shown in Figure 4 and Table 2.

Table 2 shows that the average fractal dimension of pore distribution in the coal samples was B-5 $>\mathrm{B}-4>$ B-3 $>$ B-1 $>$ B- $6>$ B-2. The maximum fractal dimension of pore distribution was observed in the B- 5 coal sample, and the minimum mean fractal dimension was observed in the B-2 coal sample. The average fractal dimensions of the B-1, B-3, B-4, and B-6 coal samples were in the middle, with no significant differences. Fractal theory states that the larger the fractal dimension of coal pore distribution, the more developed the pores and the more uneven the distribution. Therefore, the B-5 coal seam was found to have the most developed pores and the most uneven distribution, with the most undeveloped pores being found in the B-2 coal seam, which was basically consistent with the analysis in Figure 2.

\section{Fractal Characteristics of the Internal Pores in Low-Permeability Coal Seams}

4.1. Low-Temperature Liquid Nitrogen Adsorption Experiment. To further study the internal pore structure characteristics of the low-permeability coal seam, a correlation analysis experiment of the specific surface area, the pore diameter, and the pore volume of a raw coal sample was conducted using an ASAP2020 specific surface micropore analyzer. The experimental system and experimental results are shown in Figures 5 and 6 and Table 3.

The analysis in Figure 6 shows that the adsorption capacity of the different coal seams differed when the relative pressure was the same. The adsorption capacity of the B-3 coal seam was the largest, followed by the B- 6 coal seam, with the adsorption capacities of the remaining coal seams being small; that is, B-4>B-2 $>\mathrm{B}-5>\mathrm{B}-1$.

The average pore diameter of the B- 1 to B- 6 coal seams was $10.33-32.7 \mathrm{~nm}$, the mesoporous volume proportion was more than $51 \%$, and the large pore volume ratio was between 17.59 and $48.55 \%$. The specific mesoporous surface area was more than $50 \%$, and the macroporous specific surface area was 5.92 to $50.14 \%$ (Table 3). Therefore, it was concluded that the low-permeability coal seam in the South Junger Basin coalfield in Xinjiang belongs to mesoporous material, its pore distribution was more complex, the mesoporous was dominant, there were a certain number of large pores, and there were no micropores. The pore volume and specific surface area of the B-3 coal seam was the largest, followed by the B-6 coal seam, with the relationship between the pore volumes and specific surface areas of the other coal seams being B- $4>\mathrm{B}$ $2>\mathrm{B}-5>\mathrm{B}-1$. The results showed that there was a positive correlation between the adsorption capacities, the pore volumes, and the specific surface areas of the different coal seams.

4.2. Fractal Dimension Calculation and Analysis. From the liquid nitrogen at low-temperature isothermal adsorption experimental data for the B-1 to B-6 coal seam samples, the pore radius $r$, the corresponding volume $N_{\mathrm{V}}(\leq r)$, and the area $N_{\mathrm{S}}(\geq r)$ of each coal sample were obtained. From Formulas (9) and (14), a linear relationship between $\ln N_{V}$, $\ln \left(1-N_{\mathrm{S}}\right)$ and $\ln r$ was observed. The fractal dimensions $D_{\mathrm{V}}$ for the volume and the fractal dimensions $D_{\mathrm{A}}$ for the surface area of the different coal samples were calculated using linear fitting in the double logarithmic coordinate system using origin software (The results are shown in Figures 7-9 and Table 4).

The fitting correlation coefficients are all above 0.72 ; the results show that the fitting correlation is good.

The volume fractal dimension relationship for the coal seams was B-3>B-6>B-4>B-1>B-2>B-5, and the surface area fractal dimension relationship for the coal seams was B-3 $>$ B- $4>$ B- $1>$ B- $6>$ B- $5>$ B-2. The volume fractal dimension and the surface area fractal dimension for B-1, B-4, and B-6 were similar, and the general variation trends were the same, which indicated that these two methods were able to identify the pore radius distribution characteristics of the coal samples (Figure 9). The analysis showed that the fractal dimension of the B-3 coal sample was the largest; that is, it had irregular and small pore sizes, with the average pore size measured by the low-temperature adsorption experiment being $10.33 \mathrm{~nm}$, the number of mesoporous being the largest, and the pore structure being the most complex. The fractal dimensions of the B-1, B-4, and B-6 coal samples were almost the same, which corresponded to the number of macropores. The fractal dimensions of the B-2 and B-5 coal samples were the smallest, which was consistent with the largest number of macropores, and the simplest pore structure. According to the analysis of Table 4 and Figure 9, the maximum/minimum pore size ratio has an effect on the correlation coefficient of the fractal dimension of coal 


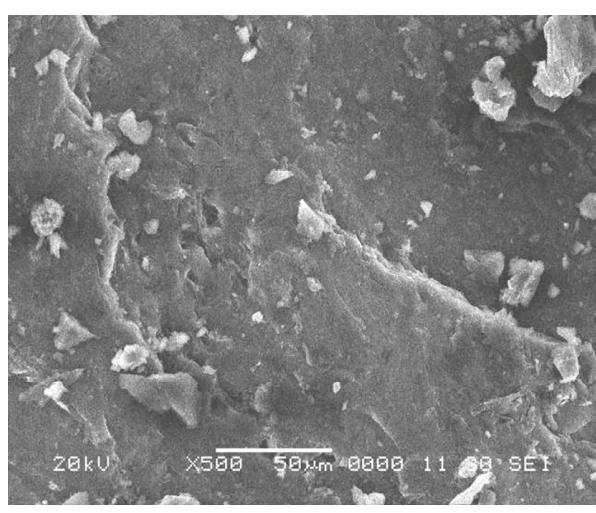

(a)

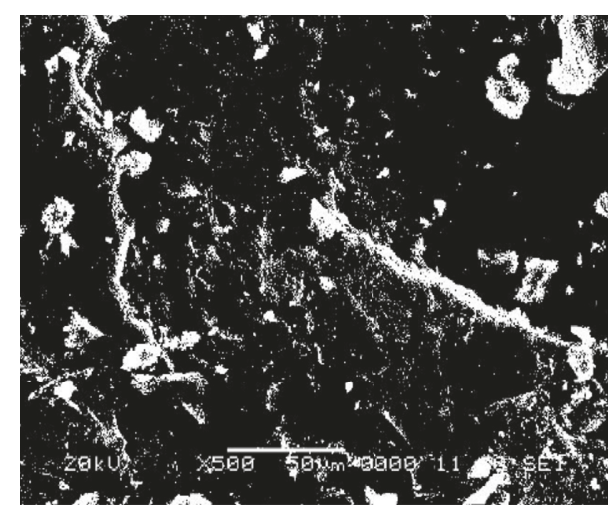

(b)

Figure 3: (a) SEM diagram and (b) binary diagram for the B-1 coal sample magnified 500-fold.

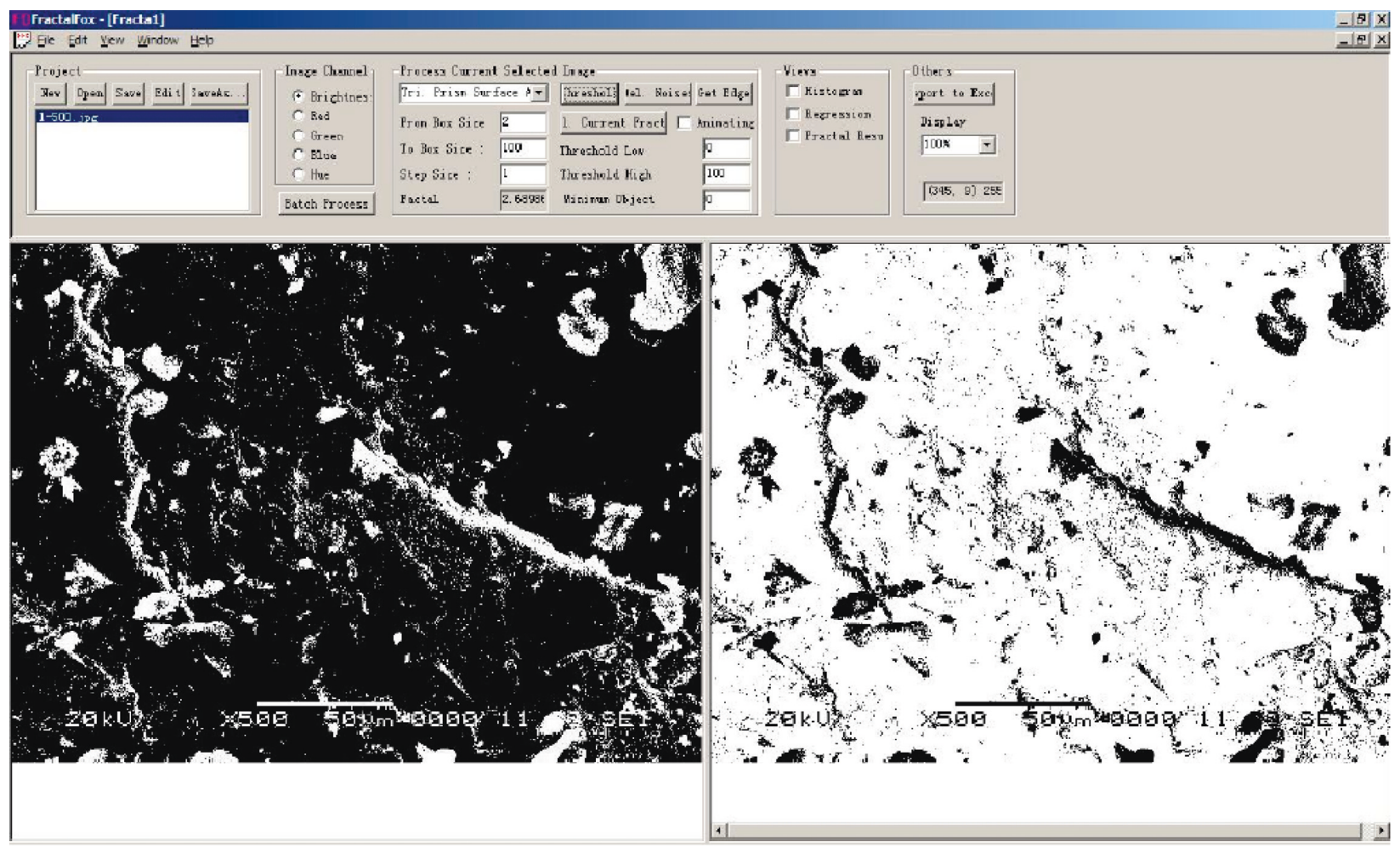

(a)

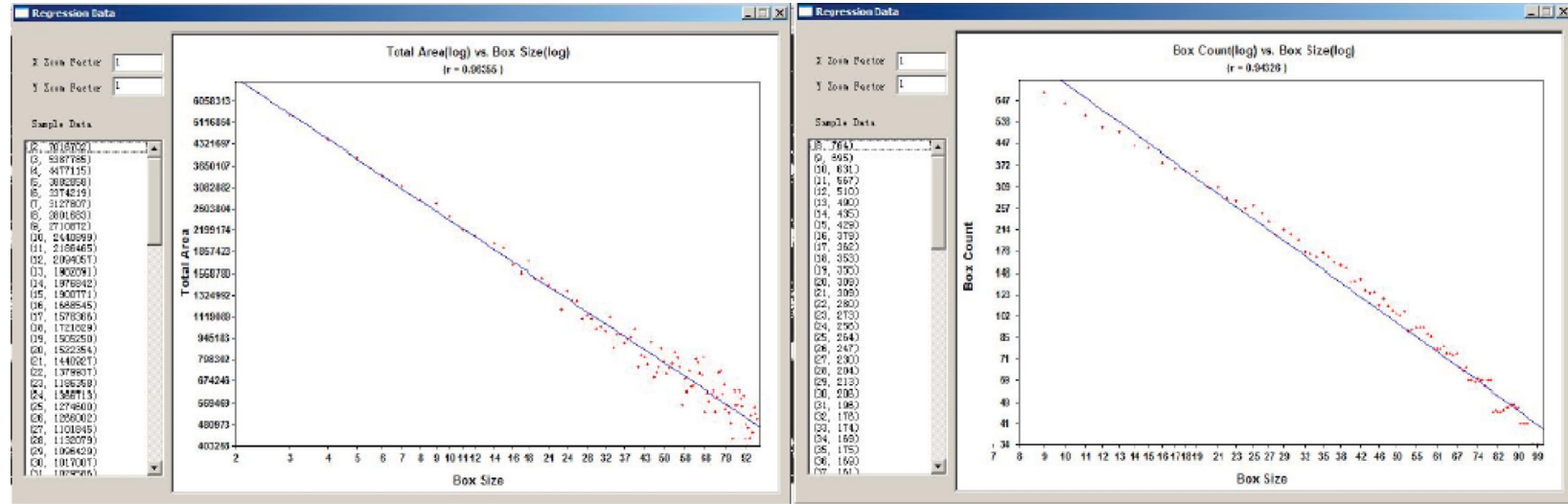

(b)

Figure 4: Calculation of the interface and pore distribution fractal dimension fitting curve using Fractal Fox 2.0 Software. 
TABle 2: Fractal dimensions of pore distribution of raw coal samples.

\begin{tabular}{|c|c|c|c|c|}
\hline $\begin{array}{l}\text { Coal } \\
\text { sample }\end{array}$ & Magnification & $\begin{array}{c}\text { Fractal } \\
\text { dimension }\end{array}$ & $R^{2}$ & $\begin{array}{l}\text { Mean fractal } \\
\text { dimension } D_{\mathrm{D}}\end{array}$ \\
\hline \multirow{5}{*}{ B-1 } & 500 & 1.9031 & 0.94326 & \multirow{5}{*}{1.7468} \\
\hline & 1000 & 1.7569 & 0.97957 & \\
\hline & $1000+$ & 1.6339 & 0.93567 & \\
\hline & 2000 & 1.7815 & 0.96458 & \\
\hline & $2000+$ & 1.6586 & 0.94362 & \\
\hline \multirow{5}{*}{ B-2 } & 500 & 1.7058 & 0.95124 & \multirow{5}{*}{1.45716} \\
\hline & 1000 & 1.3135 & 0.96959 & \\
\hline & $1000+$ & 1.5879 & 0.97451 & \\
\hline & 2000 & 1.1818 & 0.93462 & \\
\hline & $2000+$ & 1.4968 & 0.96786 & \\
\hline \multirow{5}{*}{ B-3 } & 500 & 1.9612 & 0.97896 & \multirow{5}{*}{1.79388} \\
\hline & 1000 & 1.4917 & 0.96323 & \\
\hline & $1000+$ & 1.8141 & 0.93417 & \\
\hline & 2000 & 1.8078 & 0.97489 & \\
\hline & $2000+$ & 1.8946 & 0.96587 & \\
\hline \multirow{5}{*}{ B-4 } & 500 & 1.8544 & 0.99452 & \multirow{5}{*}{1.7989} \\
\hline & 1000 & 1.6664 & 0.9764 & \\
\hline & $1000+$ & 1.9731 & 0.96312 & \\
\hline & 2000 & 1.6586 & 0.94754 & \\
\hline & $2000+$ & 1.842 & 0.96851 & \\
\hline \multirow{5}{*}{ B-5 } & 500 & 1.9859 & 0.98394 & \multirow{5}{*}{1.8371} \\
\hline & 1000 & 1.7858 & 0.97153 & \\
\hline & $1000+$ & 1.8875 & 0.96728 & \\
\hline & 2000 & 1.7415 & 0.97555 & \\
\hline & $2000+$ & 1.7848 & 0.96173 & \\
\hline \multirow{5}{*}{ B-6 } & 500 & 1.8909 & 0.94283 & \multirow{5}{*}{1.69184} \\
\hline & 1000 & 1.6697 & 0.96428 & \\
\hline & $1000+$ & 1.8521 & 0.95784 & \\
\hline & 2000 & 1.4124 & 0.92375 & \\
\hline & $2000+$ & 1.6341 & 0.97618 & \\
\hline
\end{tabular}

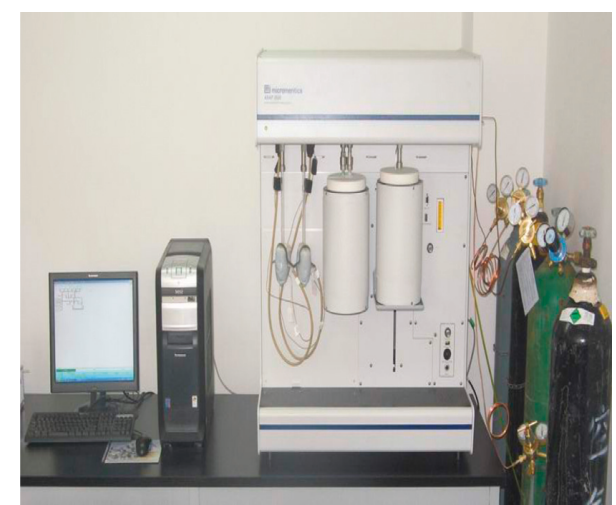

FIGURE 5: ASAP2020 specific surface microanalyzer.

sample surface area, but it has no effect on the trend of quantitative characterization of pore structure.

The fractal dimension of coal pore surface is a measure of irregular roughness of the pore surface, which reflects the comprehensive index of pore distribution, pore diameter, and pore volume of coal. Based on the low-temperature nitrogen adsorption isotherm experimental data on the coal samples, the pore surface fractal dimensions were

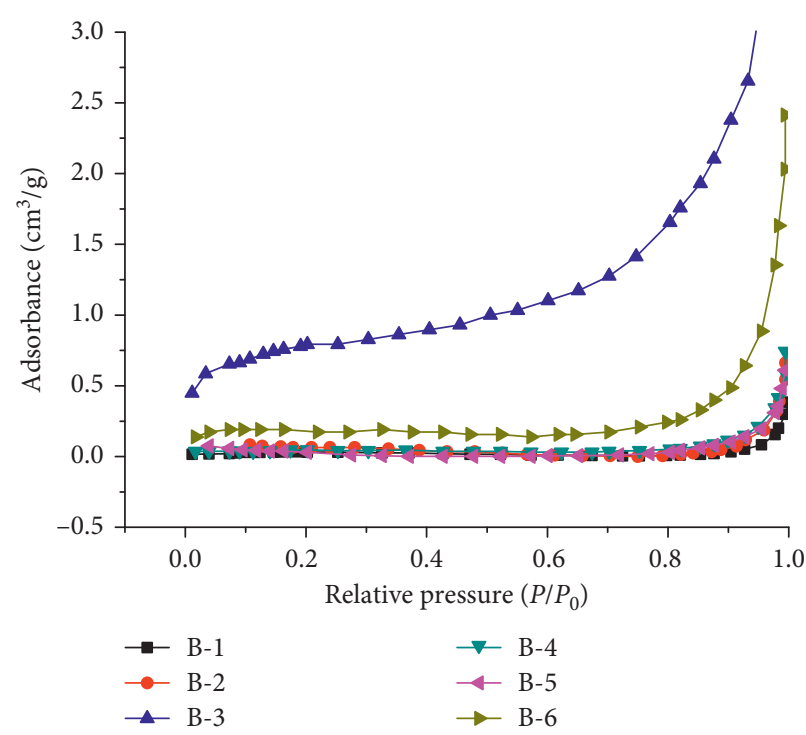

FIGURE 6: Adsorption isotherms of nitrogen for the raw coal samples.

calculated using Formula (16) (the results are shown in Figure 10).

The results show that the fitting correlation coefficient was above 0.93 , and the correlation was good.

The pore surface fractal dimension order was B-3 $>$ B$6>\mathrm{B}-4>\mathrm{B}-2>\mathrm{B}-1>\mathrm{B}-5$ (Figure 10). The pore surface fractal dimension of the B-3 coal sample was the largest, which was consistent with its complex pore structure. The pore surface fractal dimension of the B-5 coal sample was the smallest, as the pore boundary was smoother compared with the other coal samples. The pore surface fractal dimensions of B-1, B-2, and B-4 coal samples were in the middle, with similar sizes, which indicated that the pore surfaces were generally rough. The pore surface fractal dimension of B- 6 was greater than that of B-4, indicating that the pore roughness of the B-6 coal sample was greater than the pore roughness of $\mathrm{B}-4$.

\section{Relationship between Pore Fractal Dimension and Macrophysical Properties in Low-Permeability Coal Seams}

The relationships between the pore structures and the fractal dimensions were determined using origin software, the experimental data, and the fractal dimension calculation results (Figure 11).

The fractal dimension of pores in different coal seams shows a negative linear relationship with the average pore size and a positive linear relationship with total surface area and total pore volume. The results showed that the larger the average pore radius fractal dimension, the larger the pore volume and surface area. The linear relationships between the volume fractal dimension, the surface area fractal dimension, and the mesoporous surface area ratio were positively correlated. The surface fractal dimension has a positive exponential relationship with the mesoporous 
TABLE 3: Specific surface area, pore volume, and pore size of raw coal samples.

\begin{tabular}{lcccc}
\hline Coal sample & $\begin{array}{c}\text { Average } \\
\text { pore diameter }(\mathrm{nm})\end{array}$ & $\begin{array}{c}\text { Cumulative } \\
\text { pore volume }\left(\mathrm{cm}^{3} \cdot \mathrm{g}^{-1}\right)\end{array}$ & $\begin{array}{c}\text { Cumulative specific } \\
\text { surface area }\left(\mathrm{m}^{2} \cdot \mathrm{g}^{-1}\right)\end{array}$ & $\begin{array}{c}\text { Pore volume/specific surface area ratio } \\
\text { of different pore size segments }(\%) \\
\text { Macropore }(>50)\end{array}$ \\
Mesopore $(2 \sim 50)$
\end{tabular}

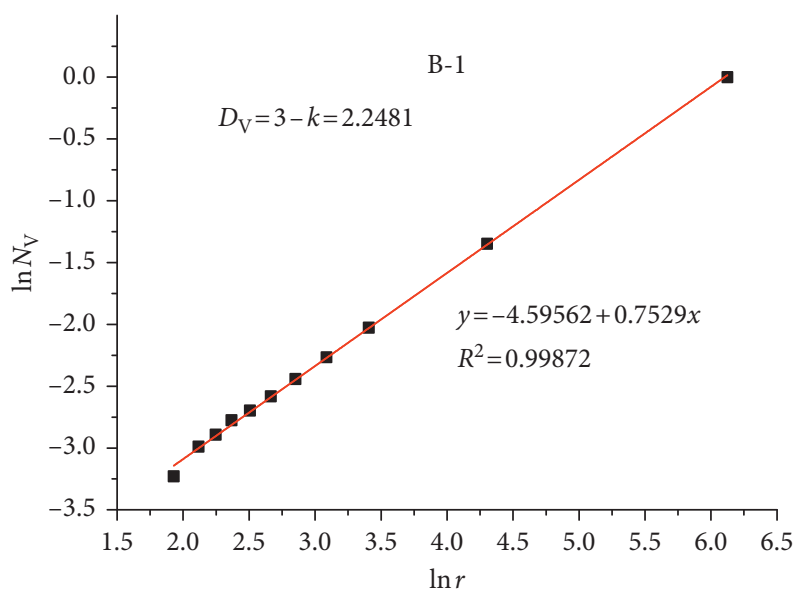

(a)

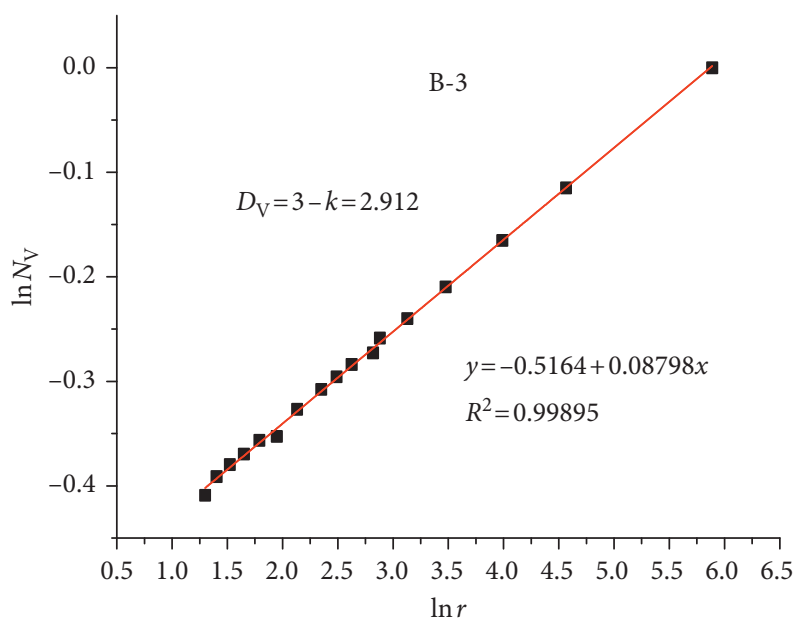

(c)

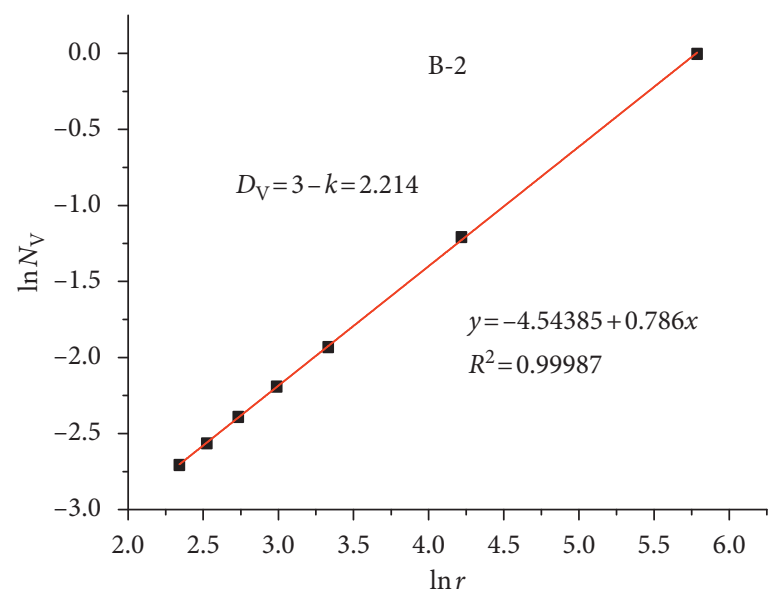

(b)

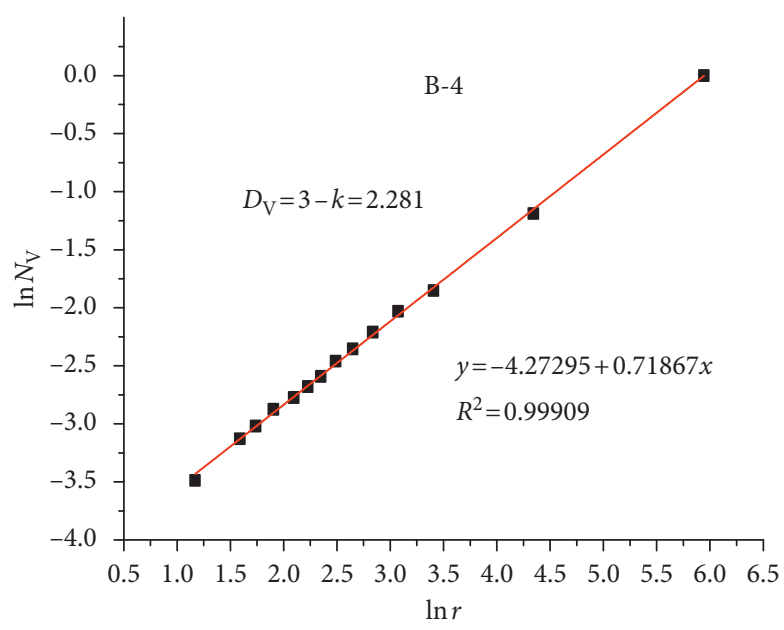

(d)

Figure 7: Continued. 


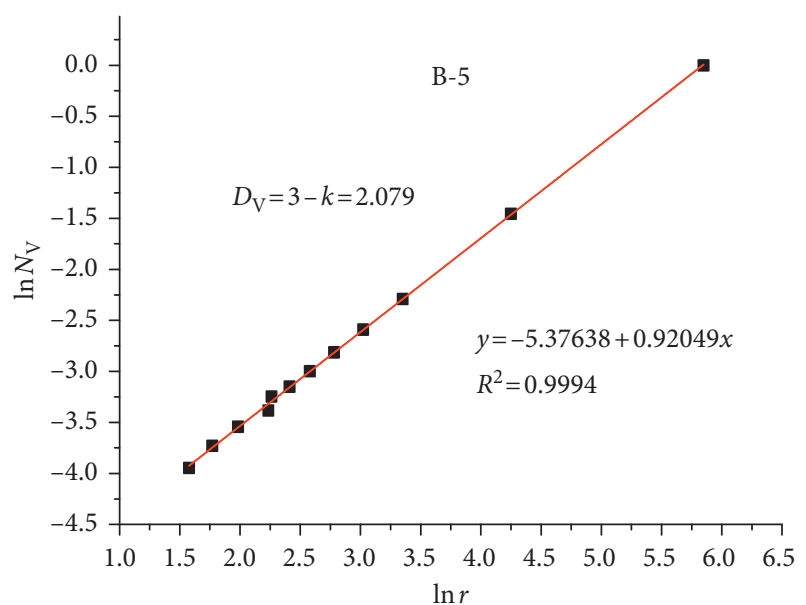

(e)

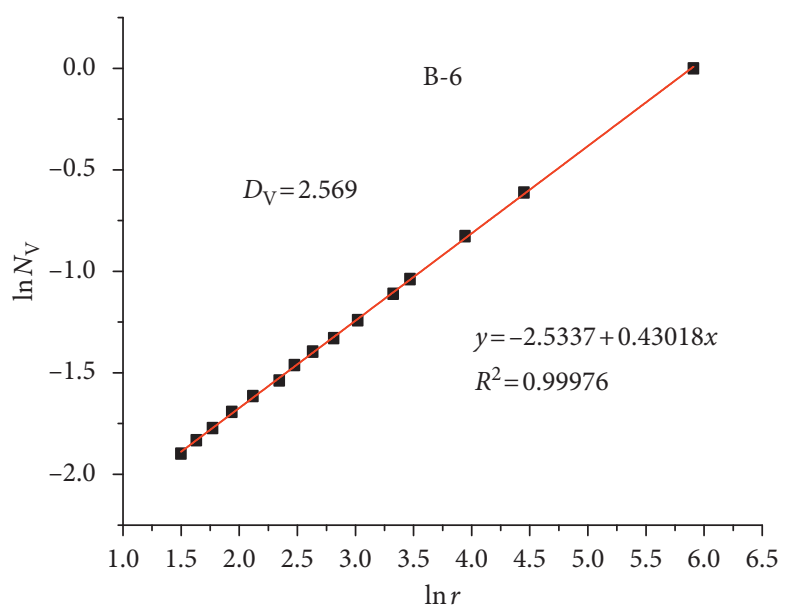

(f)

Figure 7: Calculation of pore volume fractal dimensions for the B-1 to B-6 coal samples.

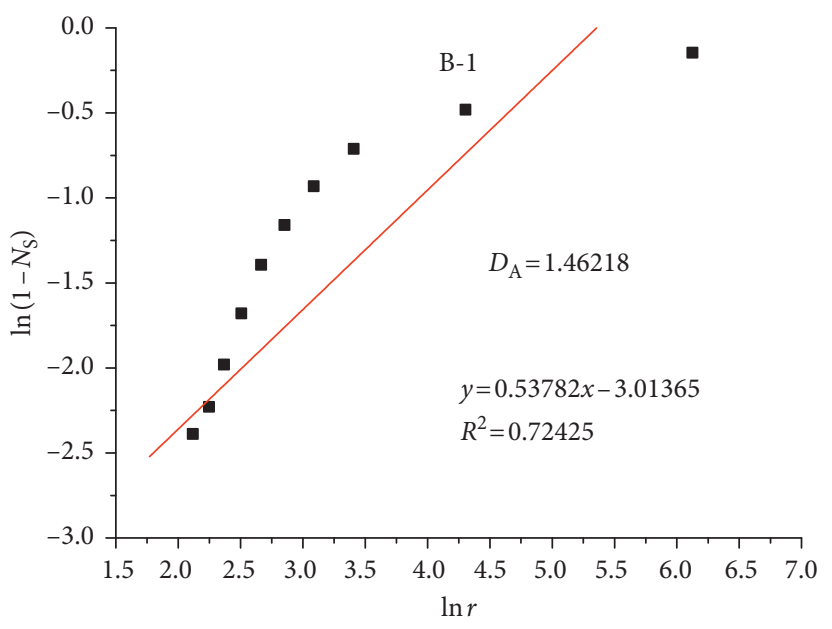

(a)

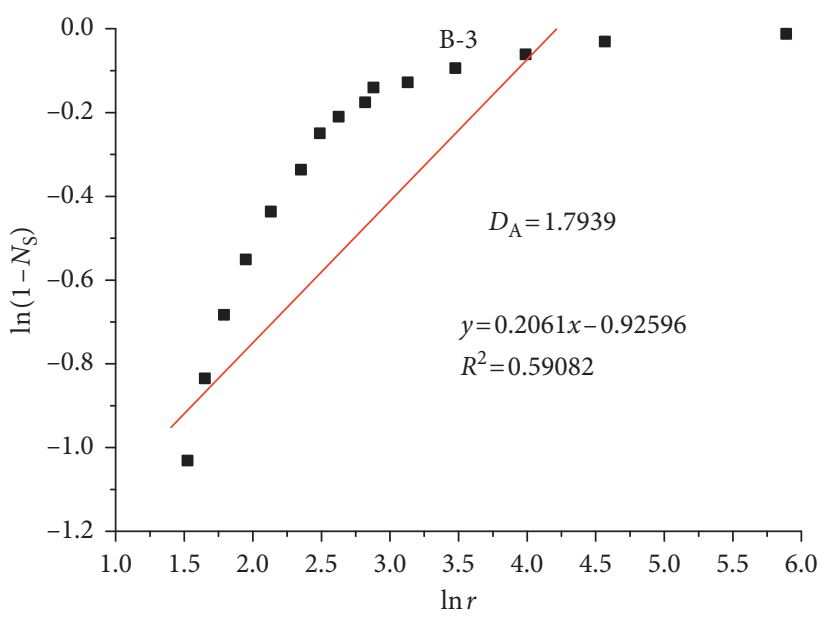

(c)

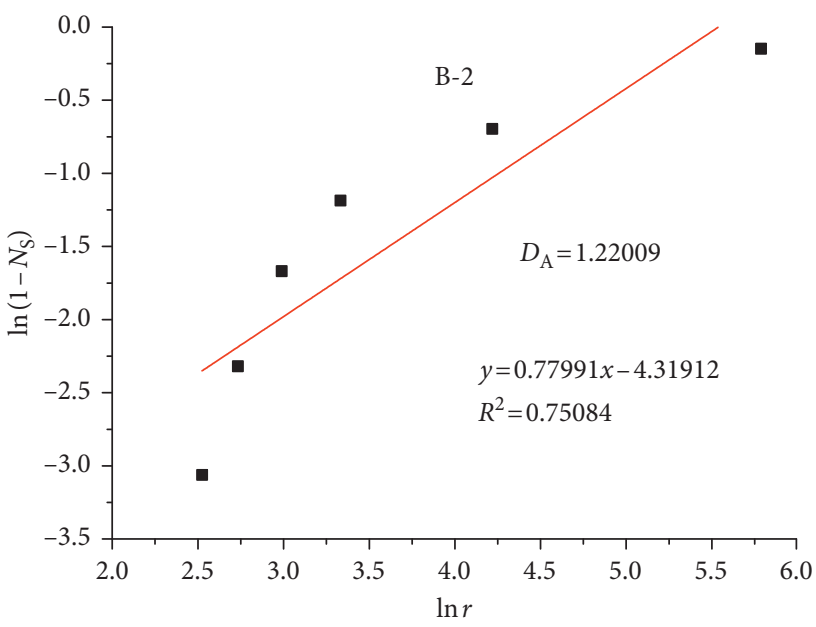

(b)

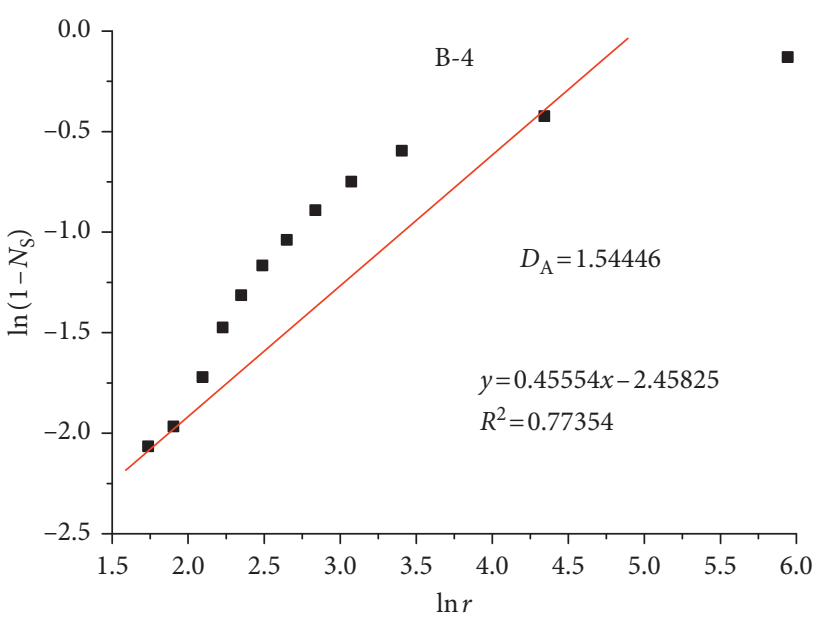

(d)

FIgure 8: Continued. 


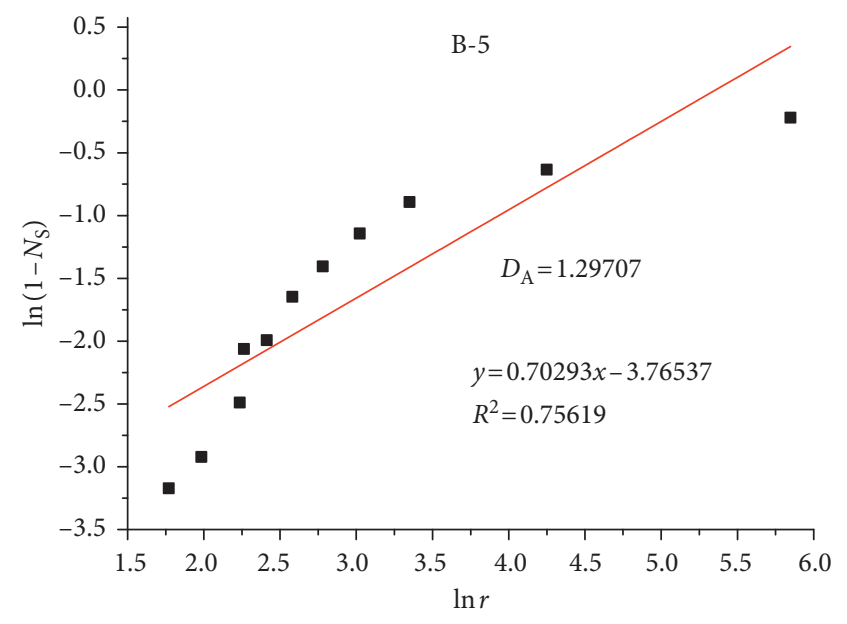

(e)

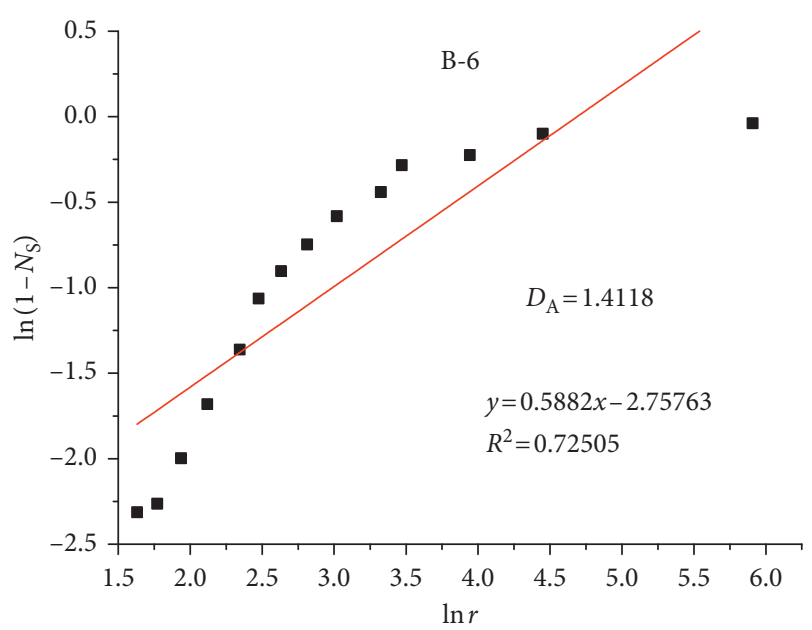

(f)

Figure 8: Calculation of pore surface area fractal dimensions for the B-1 to B-6 coal samples.

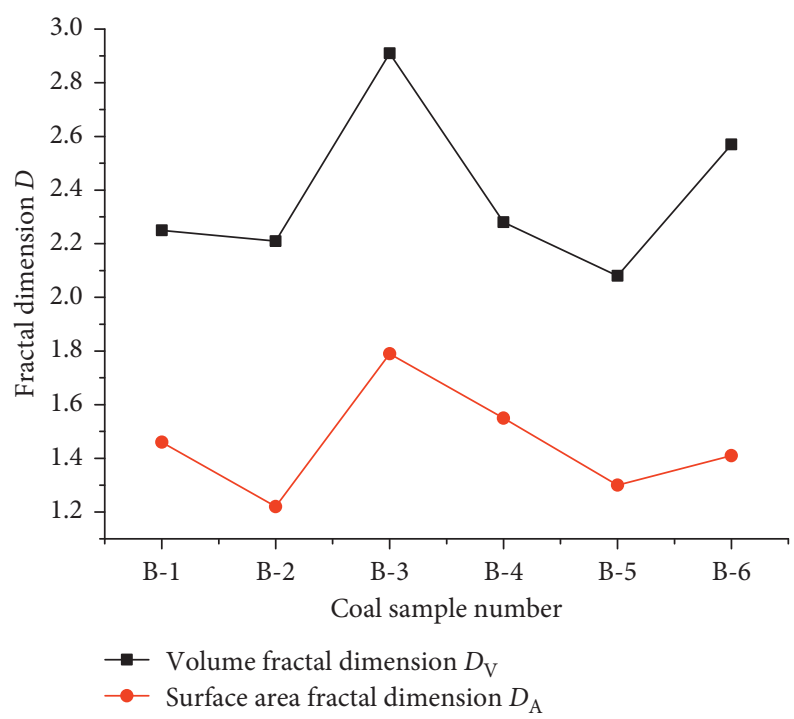

FIGURE 9: Fractal dimension of pore structure in different coal seams.

TABle 4: Maximum and minimum pore radius and volume/area fractal dimension for the B-1 to B-6 coal samples.

\begin{tabular}{lccccc}
\hline $\begin{array}{l}\text { Coal } \\
\text { sample }\end{array}$ & $\begin{array}{c}\text { Maximum/minimum pore } \\
\text { diameter }(\mathrm{nm})\end{array}$ & $\begin{array}{c}\text { Maximum/minimum } \\
\text { pore ratio }\end{array}$ & $\begin{array}{c}\text { Volume fractal } \\
\text { dimension } D_{\mathrm{V}}\end{array}$ & $R^{2}$ & $\begin{array}{c}\text { Area fractal } \\
\text { dimension } D_{\mathrm{A}}\end{array}$ \\
\hline B-1 & $193.31 / 3.7$ & 52.24595 & 2.25 & 0.99872 & 1.46 \\
B-2 & $179.56 / 8.86$ & 20.26637 & 2.21 & 0.99987 & 0.72425 \\
B-3 & $97.71 / 3.25$ & 30.06461 & 2.91 & 0.99895 & 1.22 \\
B-4 & $133.19 / 3.01$ & 44.24917 & 2.28 & 0.99909 & 0.75084 \\
B-5 & $152.66 / 2.64$ & 57.82576 & 2.08 & 0.9994 & 0.59082 \\
B-6 & $111.49 / 3.56$ & 31.31742 & 2.57 & 0.99976 & 1.55 \\
\hline
\end{tabular}

surface area ratio. In general, the higher the fractal dimensions of the pores in the different coal seams, the larger the mesoporous proportion.

The results showed that coal seam permeability is related to the porosity development degree outside the coal seam. The permeability of B-3 and B-4 was basically consistent, and the corresponding fractal dimensions were basically the same; however, as the permeability of B-2 and B-6 was larger, the corresponding fractal dimensions were the smallest. There was a stage negative correlation found 


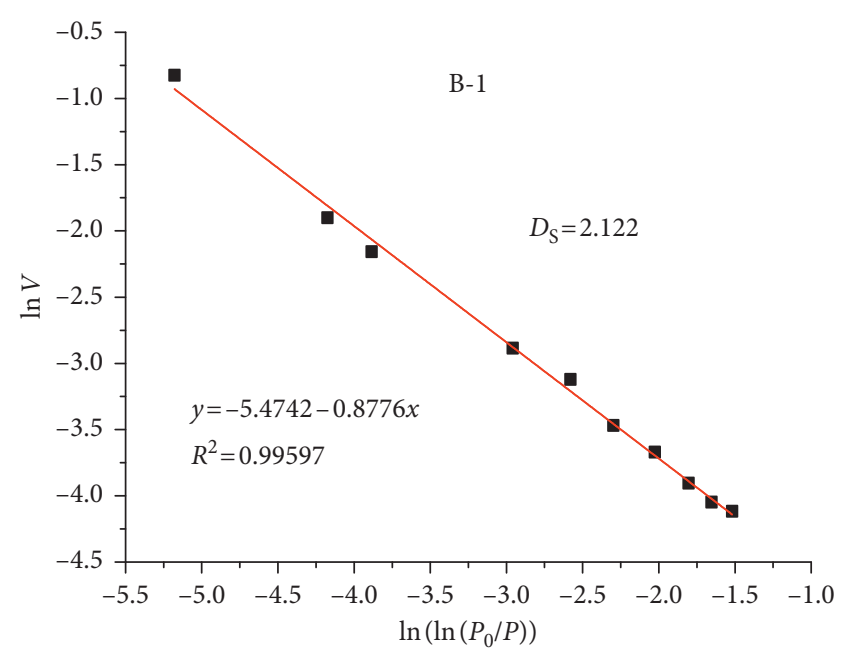

(a)

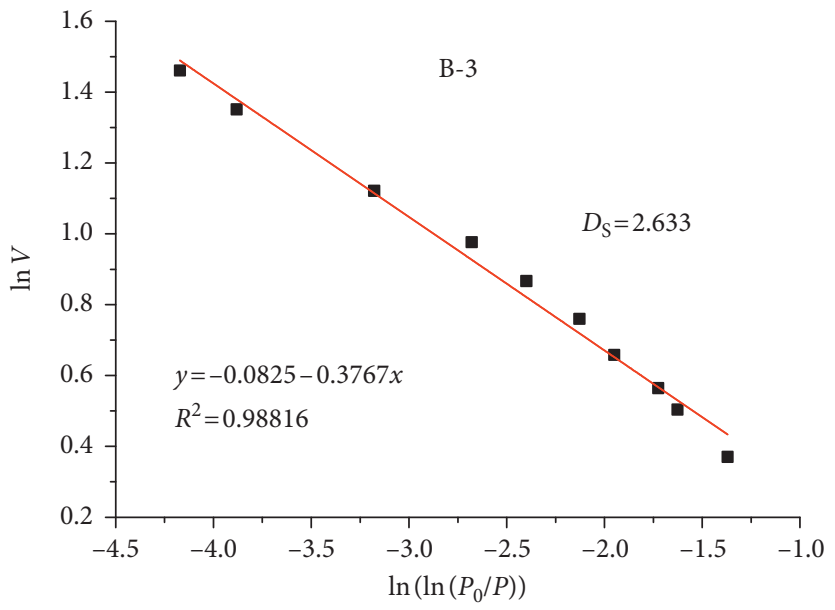

(c)

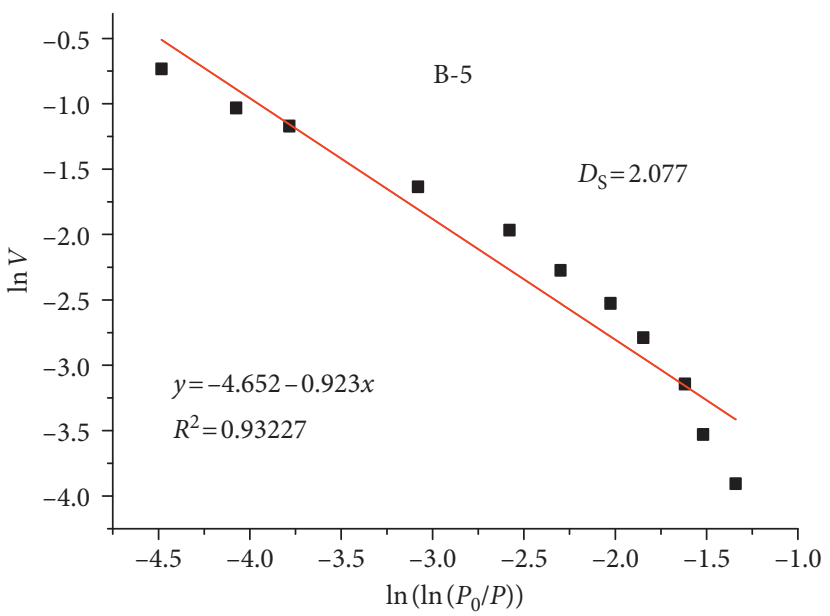

(e)

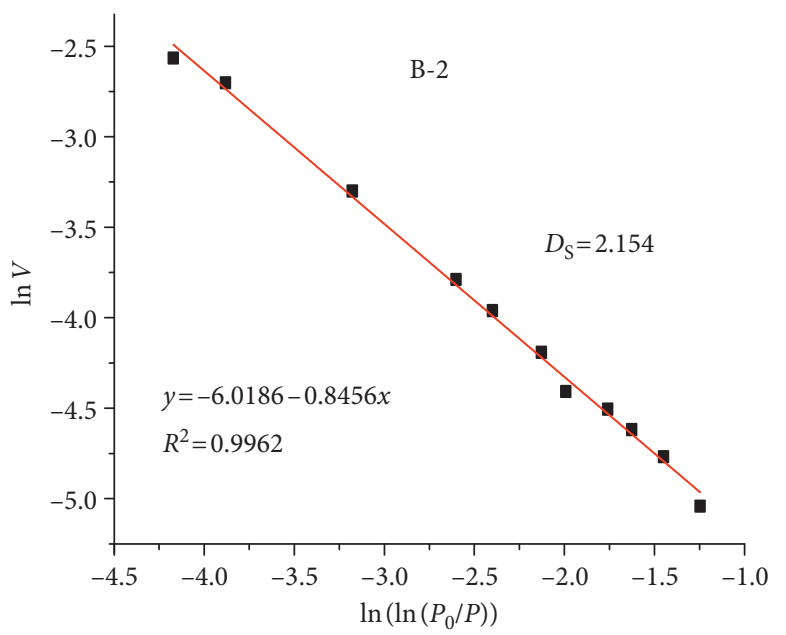

(b)

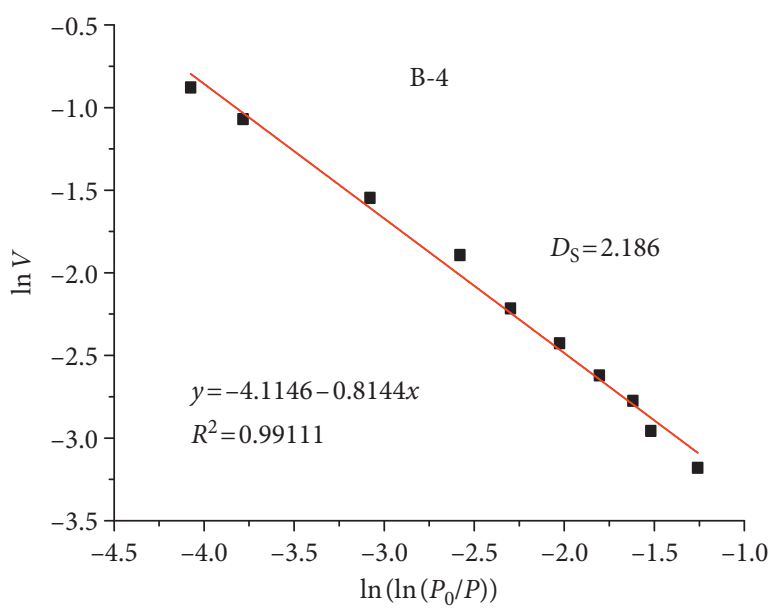

(d)

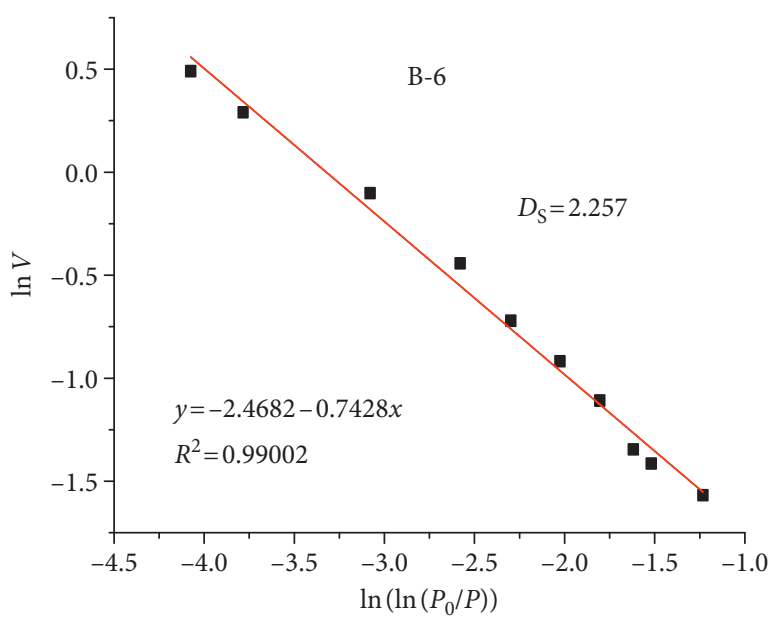

(f)

FIgURE 10: Calculation of pore surface fractal dimension for the B-1 to B-6 coal samples.

between permeability and the pore distribution fractal dimension and a positive correlation found between permeability and porosity (Figure 12). Therefore, these results were consistent with the conclusion that porous media permeability decreases with an increase in the fractal dimension and pore structure complexity [45]. The fractal dimension of pore distribution in different coal seams was B-5 $>$ B- $4>$ B-3 $>$ B-1 $>$ B- $6>$ B-2, which indicated that the 

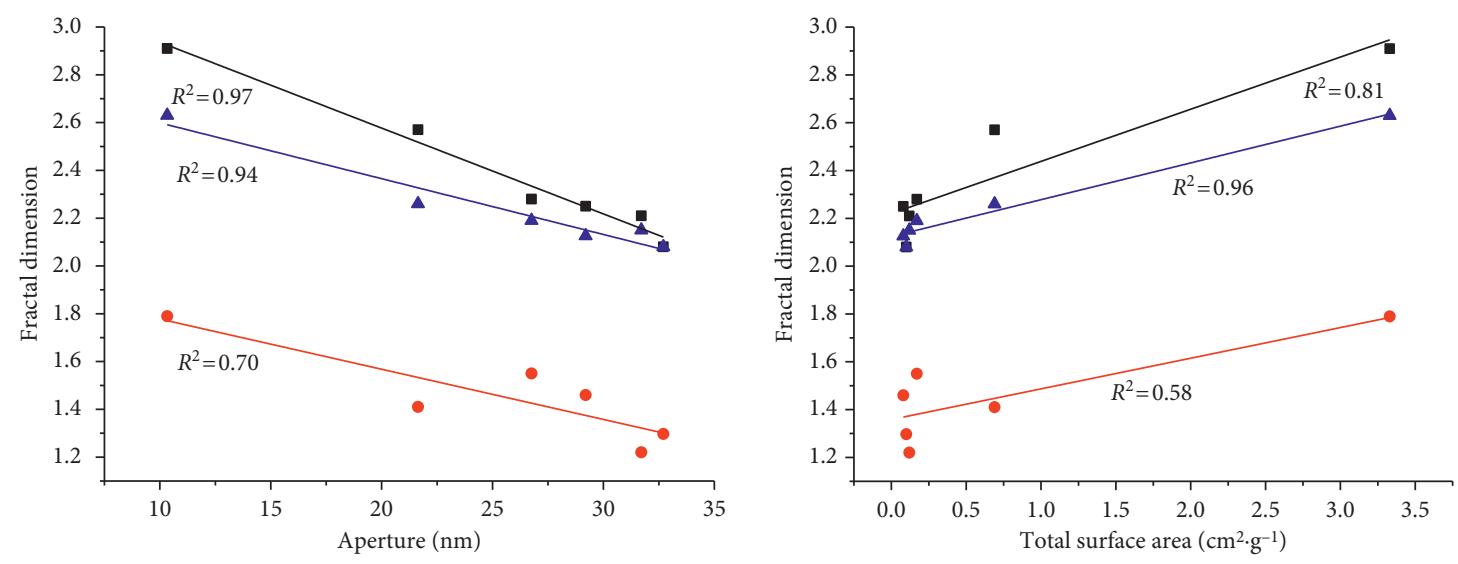

- Volume fractal dimension $D_{\mathrm{V}}$

- Area fractal dimension $D_{\mathrm{A}}$

- Surface fractal dimension $D_{\mathrm{S}}$

(a)

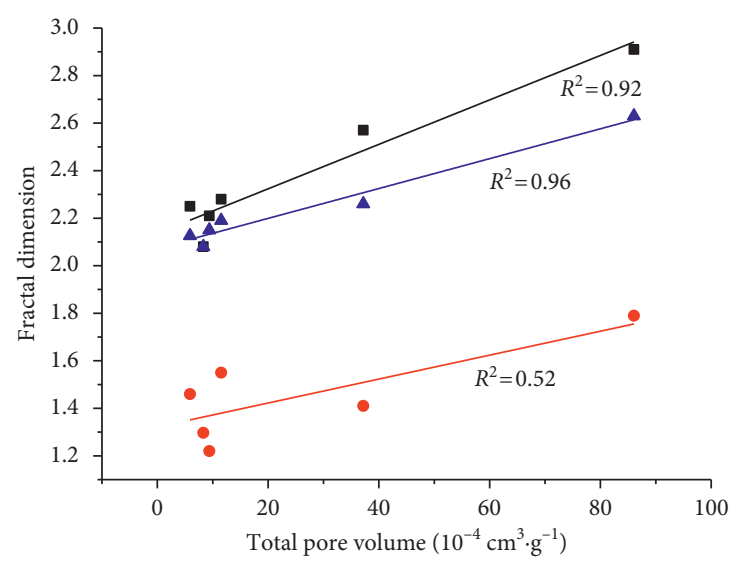

- Volume fractal dimension $D_{V}$

- Area fractal dimension $D_{\mathrm{A}}$

- Surface fractal dimension $D_{\mathrm{S}}$

(b)

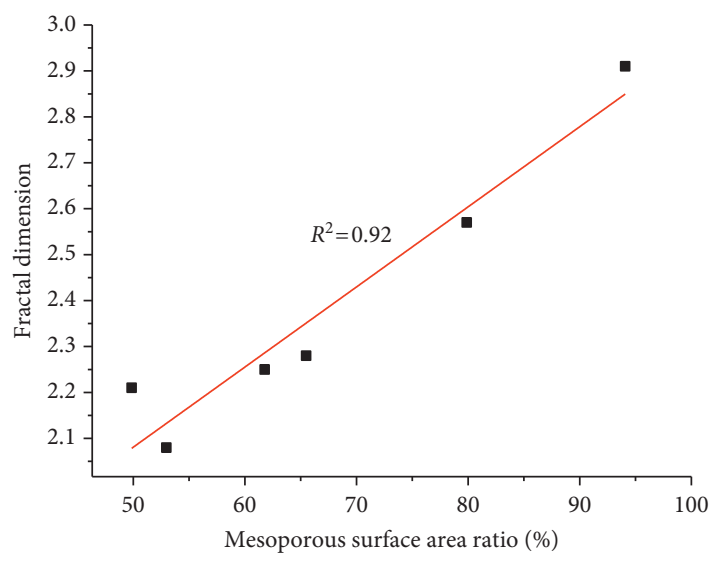

- Volume fractal dimension $D_{\mathrm{V}}$

Volume fractal dimension $D$

- Area fractal dimension $D_{\mathrm{A}}$

- Surface fractal dimension $D_{\mathrm{S}}$

- Linear fit of $D_{\mathrm{V}}$

(c)

(d)

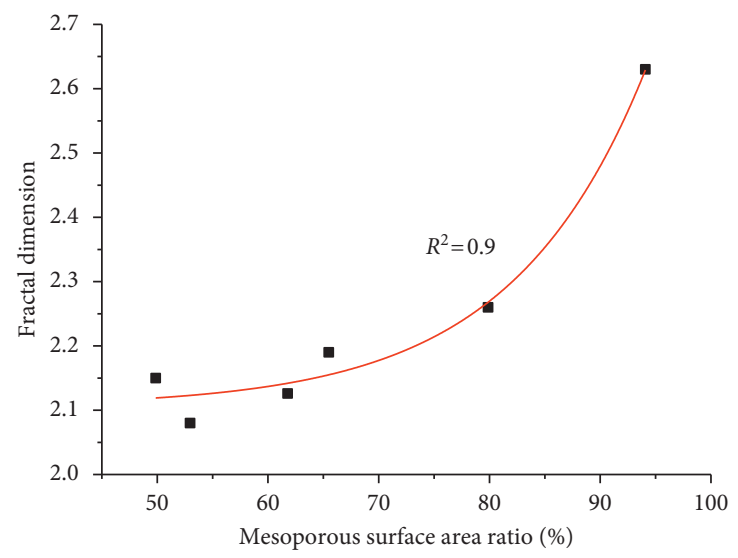

- Surface fractal dimension $D_{\mathrm{S}}$

- ExpGro2 fit of $D_{\mathrm{S}}$

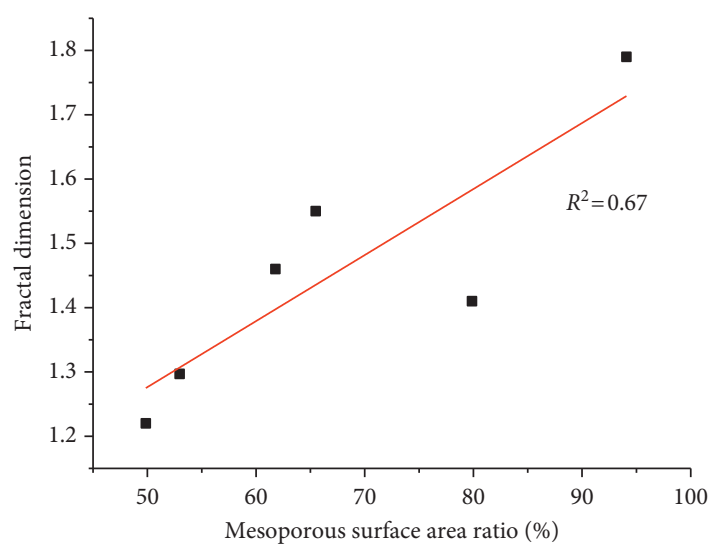

- Area fractal dimension $D_{\mathrm{A}}$

_ Linear fit of $D_{\mathrm{A}}$

(e)

(f)

FIGURE 11: Relationship between the pore fractal dimension and the pore structure parameters for the B-1 to B-6 coal samples. 


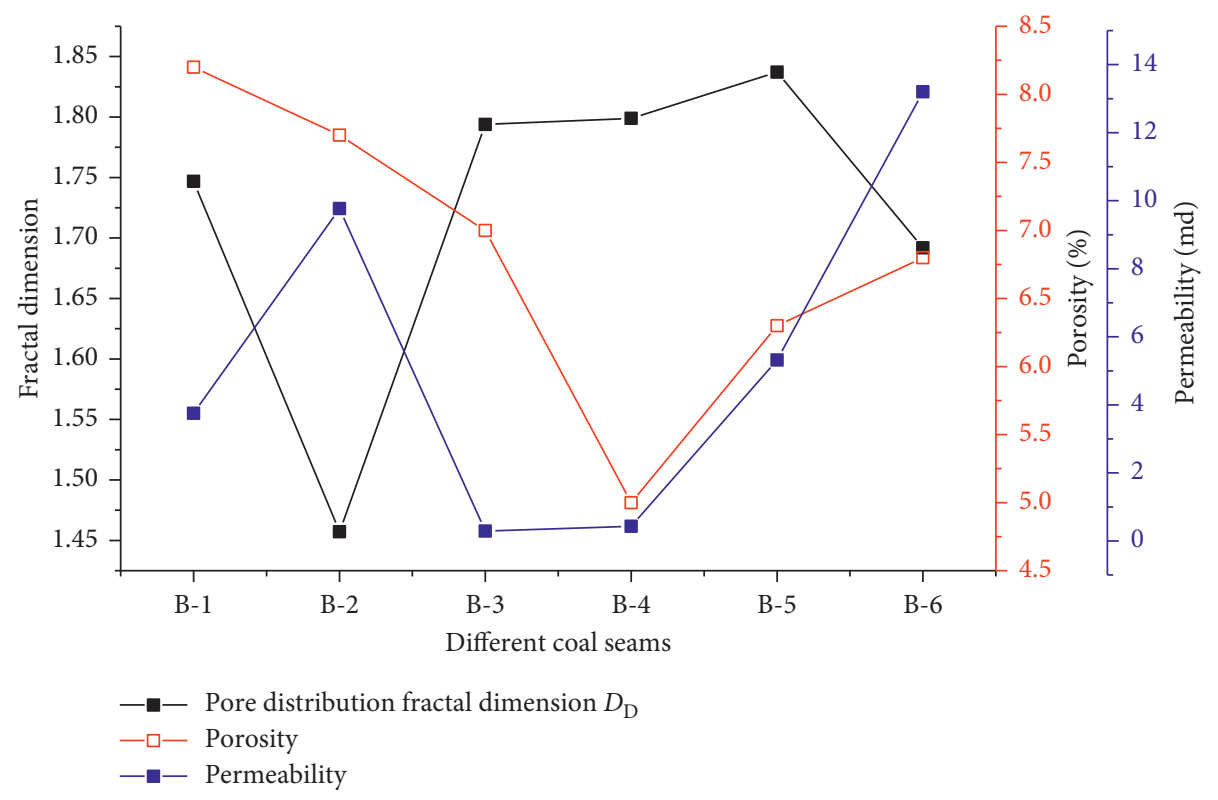

Figure 12: Fractal dimension, porosity, and permeability for the B-1 to B-6 coal samples.

distribution of the B-5 pores was the most uneven in the plane images, as shown in Figure 2.

The results showed that the adsorption capacity of the different coal seams was consistent with the change trend of mesoporous surface area, and mesopore is the main part of pore adsorption in low-permeability coal seams (Figure 13). With the increase of mesoporous surface area, the surface roughness increases and the adsorption ability of the coal mesoporous surface increases.

The surface fractal dimension measures the pore surface characteristics and reflects the adsorption ability of the coal seam. The adsorption capacity of raw coal in low-permeability coal seams has a positive linear relationship with the surface fractal dimension (Figure 14), with the relationship being: $y=7.76942 x-16.17684 ; 2 \leq x \leq 3 ; R^{2}=0.93$.

\section{Conclusions}

This article took the raw coal from a typical low-permeability coal seam in the coalfield of South Junger Basin in Xinjiang as the research object to examine the microscopic pore structures and fractal characteristics of low-permeability coal seams using a high-resolution scanning electron microscope (SEM), fractal software (Fractal fox2.0), and a specific surface microporous analyzer (ASAP2020). The main conclusions were as follows:

(1) From the principles of fractal geometry, a fractal dimension calculation model for the volume, surface area, surface, and pore distribution for the coal micropore structures was established. The validity of the fractal model was verified by a scanning electron microscope and a nitrogen adsorption test at low temperature.

(2) The low-temperature nitrogen adsorption test found that the typical low-permeability coal seam in the coalfield of South Junger Basin in Xinjiang

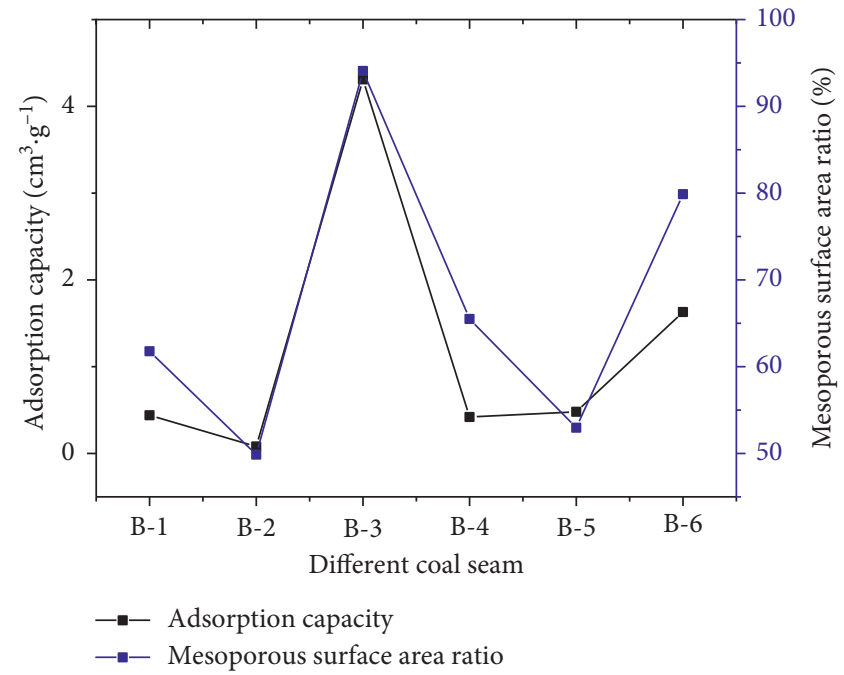

Figure 13: Adsorption capacity and mesoporous surface area for the B-1 to B-6 coal samples.

belongs to the mesoporous medium, which is mainly mesoporous, with a certain amount of large pores, no micropores, and a more complex pore distribution. Under the same pressure conditions, a positive correlation was found between the adsorption capacity, the pore volume, and the specific surface area of the coal seam.

(3) The pore fractal dimensions and the pore structural parameters were fitted using origin software, from which it was found that the pore fractal dimension in low-permeability coal seams has a negative linear relationship with average pore size, a positive linear relationship with total surface area and total pore volume, and a positive correlation with the mesoporous surface area ratio; that is, the higher the 


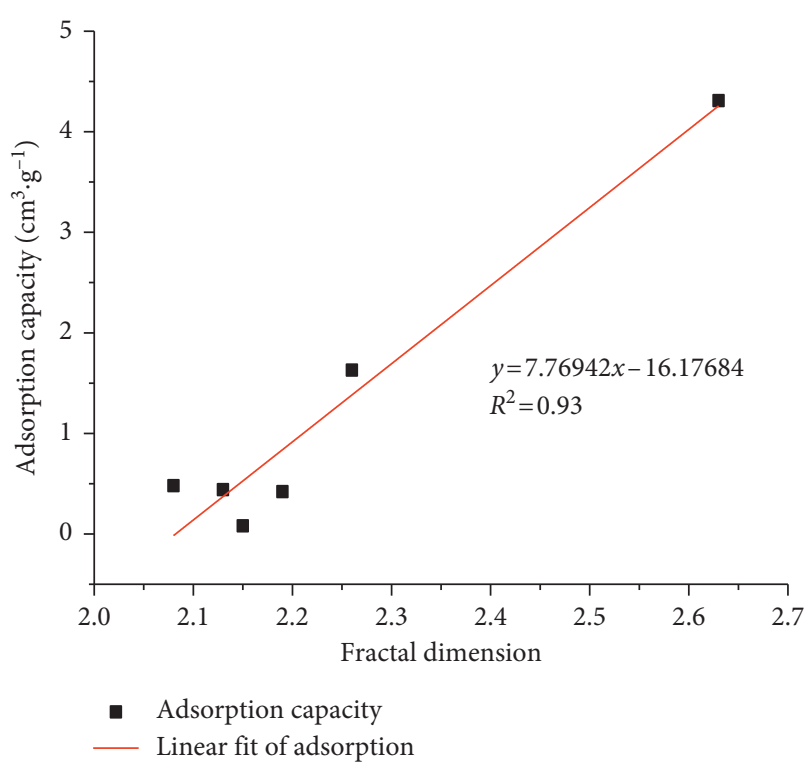

Figure 14: Relationship between adsorption quantity and pore surface fractal dimension.

fractal dimension, the larger the pore volume, surface area, and mesoporous surface area.

(4) The permeability of low-permeability coal seams has a phase correlation with the micropore development degree. Permeability was found to have a phase negative correlation with the pore distribution fractal dimension and a positive correlation with permeability and porosity, which indicated that the micropore has an important influence on the permeability of low-permeability coal seams.

(5) The study on the relationships between pore adsorption capacity, mesoporous surface area, and surface fractal dimensions in low-permeability coal seams showed that coal seam adsorption capacity was positively related to mesoporous surface area because of the mesopores and had a positive linear relationship with the surface fractal dimension, which can quantitatively characterize the adsorption capacity of the coal seam. These results could be of significant value when assessing the adsorption characteristics for coal bed methane exploration.

\section{Data Availability}

The data used to support the findings of this study are available from the corresponding author upon request.

\section{Conflicts of Interest}

The authors declare that they have no conflicts of interest.

\section{Acknowledgments}

This work was supported by Major Scientific and Technological Projects of "13115" Science and Technology
Innovation Project in Shaanxi (2009ZDKG57), Science and Technology to Support Major Projects in Xinjiang (2014AB025), and the Major Projects of the Natural Science and Education in Shaanxi (2015JS060).

\section{References}

[1] C. H. Guo, X. Wu, C. W. Zhang, C. Wangang, and Z. Hao, "Characterization of micro-structure in coalbed methane reservoir to appraise reservoir quality," Journal of Nanoscience and Nanotechnology, vol. 17, no. 9, pp. 6859-6866, 2017.

[2] Y. F. Xu and P. Dong, "Fractal approach to hydraulic properties in unsaturated porous media," Chaos, Solitons \& Fractals, vol. 19, no. 2, pp. 327-337, 2004.

[3] M. Mahamud, O. Lopez, J. J. Pis, and J. A. Pajares, "Textural characterization of coals using fractal analysis," Fuel Processing Technology, vol. 81, no. 2, pp. 127-142, 2003.

[4] M. R. Othman, Z. Helwani, and Martunus, "Simulated fractal permeability for porous membranes," Applied Mathematical Modelling, vol. 34, no. 9, pp. 2452-2464, 2010.

[5] Ş. Țălu, Micro and Nanoscale Characterization of Three Dimensional Surfaces. Basics and Applications, Napoca Star Publishing House, Cluj-Napoca, Romania, 2015.

[6] B. Meng, "Determination and interpretation of fractal properties of the sandstone pore system," Materials and Structures, vol. 29, no. 4, pp. 195-205, 1996.

[7] S. G. Qin, H. L. Wu, M. B. Tian, J. C. Wu, and S. L. Yao, "Fractal characteristics of the pore structure of low permeability sandstone," Applied Mechanics and Materials, vol. 190191, pp. 482-486, 2012.

[8] G. Lesniak and P. Such, "Fractal approach, analysis of images and diagenesis in pore space evaluation," Natural Resources Research, vol. 14, no. 4, pp. 317-324, 2005.

[9] M. M. Mahamud and M. F. Novo, "The use of fractal analysis in the textural characterization of coals," Fuel, vol. 87, no. 2, pp. 222-231, 2008.

[10] G. Z. Deng and Y. K. Zhang, "An analysis model of the mechanics of jointed rock mass," Journal of Coal Science \& Engineering, vol. 6, no. 1, pp. 30-36, 2000.

[11] K. W. Li and R. N. Horne, "Experimental study and fractal analysis of heterogeneity in naturally fractured rocks," Transport in Porous Media, vol. 78, no. 2, pp. 217-231, 2009.

[12] S. Erdem and M. A. Blankson, "Fractal-fracture analysis and characterization of impact-fractured surfaces in different types of concrete using digital image analysis and 3D nanomap laser profilometery," Construction and Building Materials, vol. 40, pp. 70-76, 2013.

[13] Y. X. Zhao, S. Gong, C. G. Zhang, Z. Zhang, and Y. Jiang, "Fractal characteristics of crack propagation in coal under impact loading," Fractals, vol. 26, no. 2, article 1840014, 2018.

[14] Y. H. Li, G. Q. Lu, and V. Rudolph, "Compressibility and fractal dimension of fine coal particles in relation to pore structure characterization using mercury porosimetry," Particle \& Particle Systems Characterization, vol. 16, no. 1, pp. 25-31, 1999.

[15] N. Hao, Y. L. Wang, L. T. Mao, and Q. Liu, "The fractal characteristic analysis of coal pore structure based on the mercury intrusion porosimetry," Applied Mechanics and Materials, vol. 353-356, pp. 1191-1195, 2013.

[16] K. J. Li, F. G. Zeng, J. C. Cai, G. Sheng, P. Xia, and K. Zhang, "Fractal characteristics of pores in Taiyuan formation shale from Hedong coal field, China," Fractals, vol. 26, no. 2, article 1840006, 2018. 
[17] B. S. Nie, X. F. Liu, L. L. Yang, J. Meng, and X. Li, "Pore structure characterization of different rank coals using gas adsorption and scanning electron microscopy," Fuel, vol. 158, pp. 908-917, 2015.

[18] D. Gao, M. Li, B. Wang, B. Hu, and J. Liu, "Characteristics of pore structure and fractal dimension of isometamorphic anthracite," Energies, vol. 10, no. 11, pp. 1881-1892, 2017.

[19] S. Hou, X. Wang, X. Wang, Y. Yuan, S. Pan, and X. Wang, "Pore structure characterization of low volatile bituminous coals with different particle size and tectonic deformation using low pressure gas adsorption," International Journal of Coal Geology, vol. 183, pp. 1-13, 2017.

[20] C. Peng, C. C. Zou, Y. Q. Yang, G. Zhang, and W. Wang, "Fractal analysis of high rank coal from southeast Qinshui basin by using gas adsorption and mercury porosimetry," Journal of Petroleum Science and Engineering, vol. 156, pp. 235-249, 2017.

[21] J. Z. Liu, Z. Y. Zhang, S. K. Choi, and Y. Lu, "Surface properties and pore structure of anthracite bituminous coal and lignite," Energies, vol. 11, no. 6, pp. 1502-1515, 2018.

[22] B. M. Yu, "Analysis of flow in fractal porous media," Applied Mechanics Reviews, vol. 61, no. 5, article 050801, 2008.

[23] M. Zhao and B. M. Yu, "The fractal characterization of pore structure for some numerical rocks and prediction of permeabilities," Journal of Chongqing University, vol. 34, no. 4, pp. 88-94, 2011, in Chinese.

[24] Y. B. Yao, D. M. Liu, D. Z. Tang et al., "Fractal characterization of seepage-pores of coals from China: an investigation on permeability of coals," Computers \& Geosciences, vol. 35, no. 6, pp. 1159-1166, 2009.

[25] Y. D. Cai, D. M. Liu, Z. J. Pan, Y. Che, and Z. Liu, "Investigating the effects of seepage-pores and fractures on coal permeability by fractal analysis," Transport in Porous Media, vol. 111, no. 2, pp. 479-497, 2016.

[26] X. M. Yu, Z. S. Lu, and H. Q. Rao, "Research on permeability of porous graphite based on fractal theory," Chinese Journal of Mechanical Engineering, vol. 42, pp. 74-77, 2006, in Chinese.

[27] B. B. Gao, H. G. Li, L. Li et al., "Study of acoustic emission and fractal characteristics of soft and hard coal samples with same group," Chinese Journal of Rock Mechanics and Engineering, vol. 33, pp. 3498-3504, 2014.

[28] J. Li and X. Wu, "Research of coal pores and integrity evaluation method based on fractal theory," Applied Mechanics and Materials, vol. 670-671, pp. 258-262, 2014.

[29] B. Zhang, J. Zhu, F. He, and Y. Jiang, "Compressibility and fractal dimension analysis in the bituminous coal specimens," AIP Advances, vol. 8, no. 7, article 075118, 2018.

[30] X. Y. Zhang, C. F. Wu, and S. X. Liu, "Characteristic analysis and fractal model of the gas-water relative permeability of coal under different confining pressures," Journal of Petroleum Science and Engineering, vol. 159, pp. 488-496, 2017.

[31] Z. Liu, H. Yang, W. Y. Wang, W. Cheng, and L. Xin, "Experimental study on the pore structure fractals and seepage characteristics of a coal sample around a borehole in coal seam water infusion," Transport in Porous Media, vol. 125, no. 2, pp. 289-309, 2018.

[32] G. Z. Deng and R. Zheng, "Reconstruction of 3D micro pore structure of coal and simulation of its mechanical properties," Advances in Materials Science and Engineering, vol. 2017, Article ID 5658742, 9 pages, 2017.

[33] B. M. Yu and J. H. Li, "Some fractal characters of porous media," Fractals, vol. 9, no. 3, pp. 365-372, 2001.
[34] B. B. Mandelbrot, The Fractal Geometry of Nature, W. H. Freeman and Company, New York, NY, USA, 1982.

[35] K. Falconer, Fractal Geometry: Mathematical Foundations and Applications, John Wiley \& Sons, Hoboken, NJ, USA, 2003.

[36] C. Z. He and M. Q. Hua, "Fractal geometry description of reservoir pore structure," Oil \& Gas Geology, vol. 19, no. 1, pp. 15-23, 1998.

[37] S. H. Zhang, S. H. Tang, D. Z. Tang, W. Huang, and Z. Pan, "Determining fractal dimensions of coal pores by FHH model: problems and effects," Journal of Natural Gas Science and Engineering, vol. 21, pp. 929-939, 2014.

[38] P. Pfeifer, Y. J. Wu, M. W. Cole, and J. Krim, "Multilayer adsorption on a fractally rough surface," Physical Review Letters, vol. 62, no. 17, pp. 1997-2000, 1989.

[39] D. Avnir and M. Jaroniec, "An isotherm equation for adsorption on fractal surfaces of heterogeneous porous materials," Langmuir, vol. 5, no. 6, pp. 1431-1433, 1989.

[40] Y. B. Yin, "Adsorption isotherm on fractally porous materials," Langmuir, vol. 7, no. 2, pp. 216-217, 1991.

[41] M. Jaroniec, "Evaluation of the fractal dimension from a single adsorption isotherm," Langmuir, vol. 11, no. 6, pp. 2316-2317, 1995.

[42] Y. B. Yao, D. M. Liu, D. Tang, S. H. Tang, and W. Huang, "Fractal characterization of adsorption-pores of coals from North China: an investigation on $\mathrm{CH}_{4}$ adsorption capacity of coals," International Journal of Coal Geology, vol. 73, no. 1, pp. 27-42, 2008.

[43] J. C. Cai, F. S. J. Martinez, M. A. Martin, and E. Perfect, “An introduction to flow and transport in fractal models of porous media: part I," Fractals-Complex Geometry Patterns and Scaling in Nature and Society, vol. 22, no. 3, article 1402001, 2014.

[44] J. Xu, L. Wang, S. J. Peng et al., "Analysis of pore characteristics on the surface of raw coal under different sizes," Disaster Advances, vol. 3, no. 4, pp. 510-516, 2010.

[45] J. L. Liu, C. A. Tian, Y. W. Zeng et al., "Fractal dimensionality dependence of microstructural parameters and permeability in fractal porous media," Advances in Water Science, vol. 17, no. 6, pp. 812-817, 2006, in Chinese. 


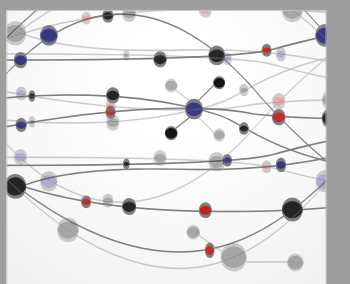

The Scientific World Journal
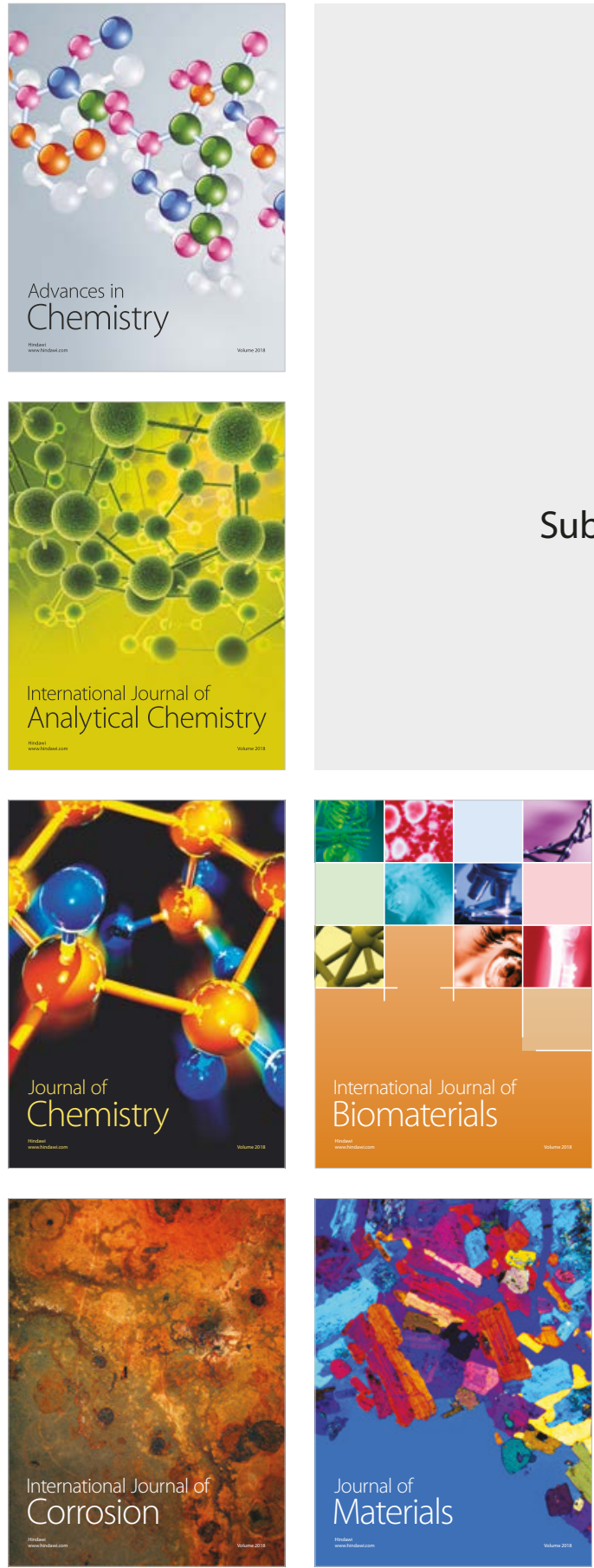

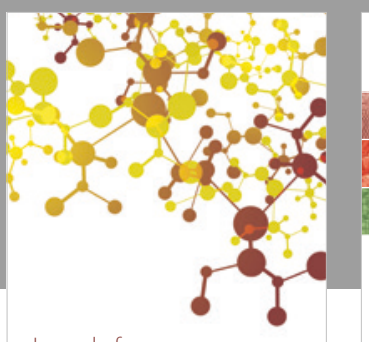

Journal of

Applied Chemistry
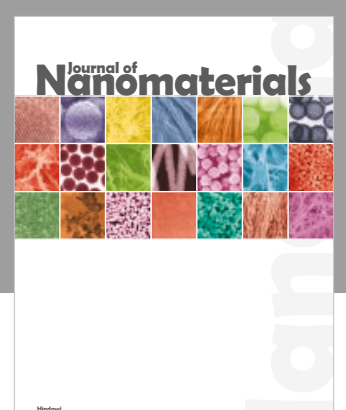

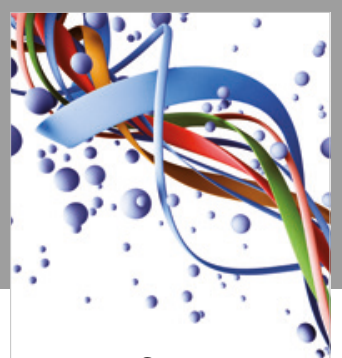

Scientifica

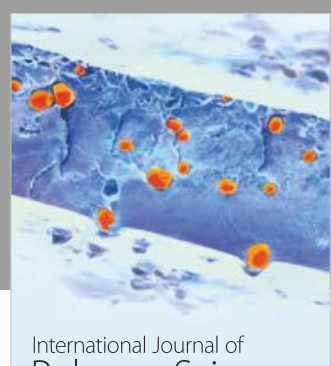

Polymer Science

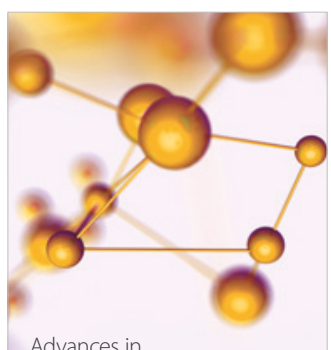

Physical Chemistry
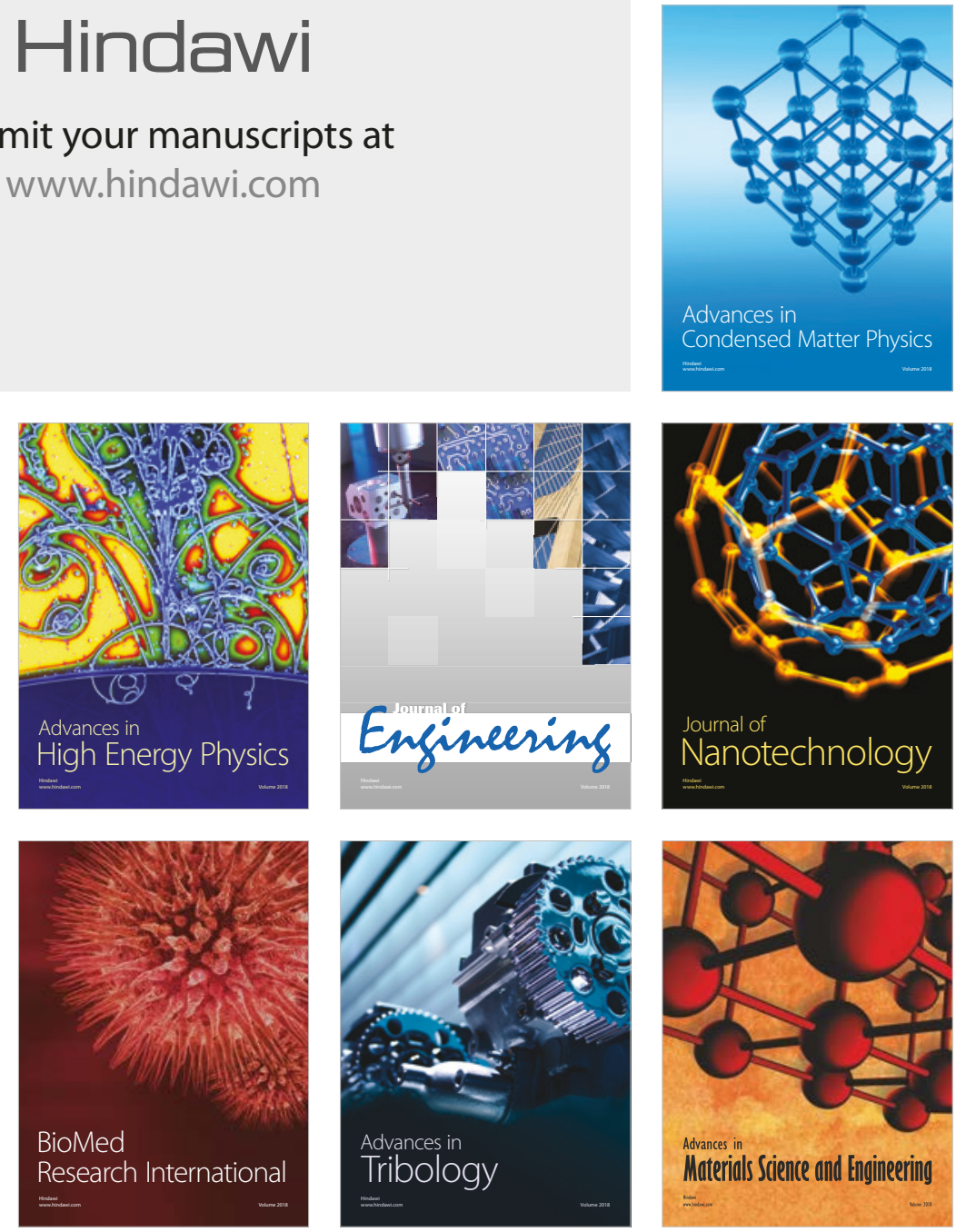